\title{
AUXERRE, Cartulaires de l'abbaye Saint-Germain
}

Les cartulaires de Saint-Germain d'Auxerre

Noëlle Deflou-Leca

\section{(2) OpenEdition}

Journals

Édition électronique

URL : https://journals.openedition.org/cem/2642

DOI : $10.4000 /$ cem. 2642

ISSN : 1954-3093

Éditeur

Centre d'études médiévales Saint-Germain d'Auxerre

Référence électronique

Noëlle Deflou-Leca, «AUXERRE, Cartulaires de l'abbaye Saint-Germain », Bulletin du centre d'études médiévales d'Auxerre / BUCEMA [En ligne], Collection CBMA, mis en ligne le 25 septembre 2007,

consulté le 24 septembre 2022. URL : http://journals.openedition.org/cem/2642 ; DOI : https://doi.org/ $10.4000 /$ cem. 2642

Ce document a été généré automatiquement le 24 septembre 2022.

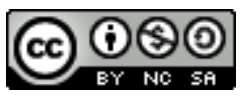

Creative Commons - Attribution - Pas d'Utilisation Commerciale - Partage dans les Mêmes Conditions 4.0 International - CC BY-NC-SA 4.0

https://creativecommons.org/licenses/by-nc-sa/4.0/ 


\title{
AUXERRE, Cartulaires de l'abbaye Saint-Germain
}

\author{
Les cartulaires de Saint-Germain d'Auxerre
}

Noëlle Deflou-Leca

1 Si le chartrier médiéval de l'abbaye n'a été que très partiellement conservé, on dispose encore aujourd'hui de deux cartulaires du monastère, rédigés dans la seconde moitié du $\mathrm{XIII}^{\mathrm{e}}$ siècle et de quatre documents réalisés au XVII ${ }^{\mathrm{e}}$ siècle qui sont qualifiés de cartulaires dans les fonds d'archives concernant des dépendances de Saint-Germain.

Le grand cartulaire (Auxerre, B.M., ms. $161 \mathrm{G}$ )

2 Conservé à la bibliothèque municipale d'Auxerre sous la cote $161 \mathrm{G}$ (anc. 142), le grand cartulaire de l'abbaye Saint-Germain est un codex composite de 216 feuillets de parchemin de grand format $(357 \mathrm{~mm} \times 256 \mathrm{~mm})$. La reliure actuelle, en veau marron clair, est du XIX ${ }^{e}$ siècle et porte les armes de la ville dans un écusson doré frappé à froid au centre du plat.

3 Rédigé pour l'essentiel dans la seconde moitié du XIII siècle, il comporte des additions ponctuelles jusqu'au XVIII ${ }^{e}$ siècle. Le préambule, qui occupe la première colonne du texte $\left(f^{\circ} 1\right)$, situe le projet de manière assez précise en $1266^{1}$. Il est commandité par l'abbé Jean de Joceval, mis en œuvre par le grainetier de l'abbaye Gui de Munois et le préchantre Gui Bocon et réalisé par le scribe anglais Walter.

Composition

4 On peut distinguer dans ce grand cartulaire trois grandes parties hétérogènes.

5 La première phase, rédigée en 1266, occupe les 97 premiers folios. Après un préambule, suivi de la table des actes complétée par différentes mains, le cartulariste a classé les chartes en onze parties. 


\begin{tabular}{|c|c|c|c|}
\hline \multicolumn{4}{|c|}{$\begin{array}{l}\text { Grand cartulaire de Saint-Germain d'Auxerre: } \\
\text { plan de la première phase de rédaction (1266) }\end{array}$} \\
\hline Feuillets & Chapitres & $\begin{array}{l}\text { Nombre } \\
\text { d'actes }\end{array}$ & $\begin{array}{l}\text { Actes ajoutés } \\
\text { postérieurement }\end{array}$ \\
\hline $1-7$ & Préambule et table & - & . \\
\hline $8-23$ & Privilèges pontificaux & 54 & 6 \\
\hline $24-39$ & Diplômes royaux et impériaux & 25 & 1 \\
\hline $40-54$ & $\begin{array}{c}\text { Actes concernant la cité d'Auxerre et ses } \\
\text { faubourgs }\end{array}$ & 38 & 12 \\
\hline $55-61$ & Actes concernant le doyenné & 31 & 3 \\
\hline $61 v^{\circ}-72$ & Actes concernant la chambre & 34 & 2 \\
\hline $72 v^{0}-78$ & Actes concernant le cellier & 27 & 1 \\
\hline $79-83 \mathrm{v}^{\circ}$ & Actes concernant Bercenay et Vauchassis & 17 & 2 \\
\hline $84-85 v^{0}$ & Actes concernant Sommecaise & 9 & 1 \\
\hline $86-91$ & Actes concernant Villiers & 10 & 2 \\
\hline $\begin{array}{l}91 \mathrm{v}^{\circ}- \\
94 \mathrm{v}^{\circ}\end{array}$ & Actes concernant Saint-Sauveur & 11 & - \\
\hline \multirow[t]{2}{*}{$95-97 \mathrm{v}^{\circ}$} & Actes concernant $\mathrm{l}^{\prime}$ infirmerie & 14 & - \\
\hline & & Total $=270$ & Total cumulé $=300$ \\
\hline
\end{tabular}

$6 \quad$ Au sein de chacune de ces parties, l'ordre chronologique n'est pas stricto censu respecté mais lorsque le cartulariste rassemble des actes qui ont trait au même sujet, il les ordonne alors selon la succession chronologique. Les privilèges pontificaux commencent ainsi par six diplômes de confirmation du temporel accordés entre 1152 et 1198 tandis que, pour les diplômes des souverains, le cartulariste néglige cette hiérarchie des actes confirmatifs placés en tête et copie les actes indépendamment de toute logique chronologique. L'ensemble de cette $1^{\text {èr }}$ phase comporte 270 actes.

7 À cette première phase s'ajoutent plusieurs continuations. Une deuxième grande campagne de rédaction copiée par une même main occupe les folios 102 à 154 . Cette phase n'est pas structurée en chapitres mais présente 96 actes au fil des cahiers sans réelle organisation géographique, chronologique ou hiérarchique.

Enfin, les soixante derniers feuillets ( $\left.f^{\circ} 155-215\right)$ ont été copiés par une quinzaine de mains différentes, certaines pour quelques actes seulement, d'autres sur plusieurs cahiers. L'agencement des 39 chartes transcrites ici suit une certaine progression chronologique en fonction des siècles même si, à l'intérieur, l'ordre strict des années n'est pas respecté : $\mathrm{XIV}^{\mathrm{e}}$ siècle ( $\left.\mathrm{f}^{\circ} 155-173\right), \mathrm{XV}^{\mathrm{e}}$ siècle (f $\left.{ }^{\circ} 175-214\right)$ et enfin XVII ${ }^{\mathrm{e}}$ siècle (fo 214). Au milieu de cet ensemble se glissent quelques actes du XIII ${ }^{e}$ siècle.

Chronologie des actes

9 Toutes phases confondues, le grand cartulaire comporte 435 actes datés de 816 à 1667 . Leur répartition chronologique s'organise de la manière suivante : 


\begin{tabular}{|c|c|}
\hline \multicolumn{2}{|c|}{ Grand cartulaire de Saint-Germain : chronologie des actes } \\
\hline $\mathrm{IX}^{\mathrm{e}}$ & 21 \\
\hline $\mathrm{X}^{\mathrm{e}}$ & 3 \\
\hline $\mathrm{XI}^{\mathrm{e}}$ & 2 \\
\hline $\mathrm{XII}^{\mathrm{e}}$ & 83 \\
\hline $\mathrm{XIII}^{\mathrm{e}}$ & 215 \\
\hline $\mathrm{XIV}^{\mathrm{e}}$ & 73 \\
\hline $\mathrm{XV}^{\mathrm{e}}$ & 18 \\
\hline $\mathrm{XVI} \mathrm{I}^{\mathrm{e}}$ & - \\
\hline XVII & 2 \\
\hline s.d. & 18 \\
\hline & Total $=435$ \\
\hline
\end{tabular}

La question des originaux conservés

Très rares sont les actes du grand cartulaire dont l'original est conservé, ce qui nous donne peu de prise pour cerner le travail des cartularistes. On en dénombre vingt pour l'ensemble du codex, soit 4,59\%. Ils se répartissent chronologiquement de la manière suivante :

\begin{tabular}{|c|c|}
$\begin{array}{c}\text { GRAND CARTULAIRE de SAINT-GERMAIN d' AUXERRE } \\
\text { Répartition chronologique des originaux conservés }\end{array}$ \\
\hline $\mathrm{IXe}^{\mathrm{e}}$ & 1 \\
\hline $\mathrm{X}^{e}$ & - \\
\hline $\mathrm{XI}^{e}$ & 1 \\
\hline $\mathrm{XII}^{e}$ & 3 \\
\hline $\mathrm{XIII}^{e}$ & 15 \\
\hline $\mathrm{XIV}^{e}$ & - \\
\hline & Total $=20$ \\
\hline
\end{tabular}

11 Leur petit nombre autorise une présentation plus précise de cette répartition selon l'ordre de transcription dans le cartulaire.

\begin{tabular}{|c|c|c|c|}
\hline \multicolumn{4}{|c|}{ Les actes originaux dans le grand cartulaire de Saint-Germain d'Auxerre } \\
\hline $\begin{array}{l}\text { Référence } \\
\text { du ms. 161G }\end{array}$ & Date & Sujet & $\begin{array}{c}\text { Lieu de } \\
\text { conservation }\end{array}$ \\
\hline P $37-38$ & 864 & $\begin{array}{l}\text { Privilège de confirmation des biens } \\
\text { du monastère par les évêques } \\
\text { réunis en concile à Pitres. }\end{array}$ & AD Yonne $\mathrm{H} 984$ \\
\hline $\mathrm{f}^{\circ} 41 \mathrm{v}^{\circ}$ & $\begin{array}{l}1238 \text {, } \\
\text { février }\end{array}$ & Vente faite à l'abbaye par un laĭc. & AD Yonne $\mathrm{H} 1159$ \\
\hline$f 41 v^{\circ}$ & $\begin{array}{l}1238 \text {, } \\
\text { février }\end{array}$ & $\begin{array}{c}\text { Approbation de la précédente vente } \\
\text { par l'évêque de Meaux. }\end{array}$ & AD Yonne $\mathrm{H} 1159$ \\
\hline$f^{\circ} 43 v^{\circ}-44$ & $\begin{array}{l}\text { 1242, } \\
\text { janvier }\end{array}$ & $\begin{array}{l}\text { Accord entre les moines de Saint- } \\
\text { Germain et les chanoines de la } \\
\text { cathédrale au sujet des processions }\end{array}$ & AD Yonne, $\mathrm{H} 999$ \\
\hline$f^{\circ} 48 v^{\circ}-49$ & $\begin{array}{l}1212 \\
1213\end{array}$ & $\begin{array}{l}\text { Accord entre les moines de Saint- } \\
\text { Germain et ceux de Saint-Marien }\end{array}$ & AD Yonne $\mathrm{H} 1215$ \\
\hline $\mathrm{f}^{\circ} 61 \mathrm{v}^{\circ}$ & 1133 & $\begin{array}{l}\text { Accord entre les moines de Saint- } \\
\text { Germain et ceux de Pontigny au } \\
\text { sujet du moulin de Spaillard. }\end{array}$ & AD Yonne $\mathrm{H} 1409$ \\
\hline$f^{\circ} 62-62 v^{\circ}$ & 1192 & $\begin{array}{l}\text { Accord entre les moines de Saint- } \\
\text { Germain et ceux de Pontigny. } \\
\text { [chirographe] }\end{array}$ & AD Yonne $\mathrm{H} 1409$ \\
\hline
\end{tabular}




\begin{tabular}{|c|c|c|c|}
\hline$f^{\circ} 63-63 v^{\circ}$ & 1231 , août & $\begin{array}{l}\text { Accord entre les moines de Saint- } \\
\text { Germain et ceux de Pontigny au } \\
\text { sujet des bois de Révisy. }\end{array}$ & AD Yonne $\mathrm{H} 1506$ \\
\hline$f^{\prime} 64-65$ & 1238, mai & $\begin{array}{l}\text { Arbitrage du chantre d'Auxerre et } \\
\text { du doyen de Tonnerre au sujet des } \\
\text { querelles entre les moines de Saint- } \\
\text { Germain et ceux de Pontigny. }\end{array}$ & AD Yonne $\mathrm{H} 1129$ \\
\hline$f^{\circ} 65-65 v^{\circ}$ & $\begin{array}{l}1240, \\
\text { février }\end{array}$ & $\begin{array}{l}\text { Lettre de l'archidiacre d'Auxerre } \\
\text { sur l'arbitrage précédent. }\end{array}$ & AD Yonne $\mathrm{H} 1506$ \\
\hline $\mathrm{f}^{\circ} 72 \mathrm{v}^{\circ}$ & 1169 & $\begin{array}{l}\text { Abandon par les moines de St- } \\
\text { Germain à ceux de Reigny de } 4 \\
\text { arpents de vigne situés à Irancy. } \\
\text { [chirographe] }\end{array}$ & AD Yonne $\mathrm{H} 1588$ \\
\hline$f^{\circ} 87-87 v^{\circ}$ & $\begin{array}{l}1224 \\
\text { septembre }\end{array}$ & $\begin{array}{l}\text { Accord entre Saint-Germain et le } \\
\text { comte de Champagne Thibaud }\end{array}$ & AD Yonne $\mathrm{H} 1192$ \\
\hline f' $88-89$ & 1244 , avril & $\begin{array}{l}\text { Accord entre les moines et Milon de } \\
\text { Saint-Florentin }\end{array}$ & AD Yonne $\mathrm{H} 1192$ \\
\hline$f^{\circ} 90 v^{0}-91$ & 1035 & $\begin{array}{l}\text { Jugement entre St-Germain et } \\
\text { Gaudri de St-Florentin au sujet de } \\
\text { Villiers-Vineux. }\end{array}$ & AD Yonne $\mathrm{H} 1192$ \\
\hline$f^{\prime} 95$ & 1209 & $\begin{array}{c}\text { Donation faite au monastère par } \\
\text { Itier Borne, sa femme ayant élu } \\
\text { sépulture dans le cimetière des } \\
\text { moines. }\end{array}$ & AD Yonne $\mathrm{H} 1146$ \\
\hline$f^{\circ} 95$ & 1210 & $\begin{array}{c}\text { Confirmation de la précédente } \\
\text { donation }\end{array}$ & AD Yonne $\mathrm{H} 1146$ \\
\hline$f^{\circ} 95-95 v^{\circ}$ & 1210 & $\begin{array}{l}\text { Confirmation de la donation de } \\
1209\end{array}$ & AD Yonne $\mathrm{H} 1146$ \\
\hline$f^{\circ} 95 v^{\circ}$ & $\begin{array}{l}1258 \\
\text { février }\end{array}$ & $\begin{array}{l}\text { Confirmation de la donation de } \\
1209\end{array}$ & AD Yonne $\mathrm{H} 1146$ \\
\hline $\mathrm{f}^{\circ} 95 \mathrm{v}^{\circ}$ & 1215 & $\begin{array}{l}\text { Donation faite au monastère d'une } \\
\text { maison à Provins. }\end{array}$ & AD Yonne $\mathrm{H} 1169$ \\
\hline$f^{0} 96 v^{\prime \prime}-97$ & $\begin{array}{l}1261, \\
\text { février }\end{array}$ & $\begin{array}{l}\text { Confirmation du legs fait à St- } \\
\text { Germain par Mabille, femme Itier } \\
\text { Borne }\end{array}$ & AD Yonne H 1146 \\
\hline
\end{tabular}

Tradition

12 La tradition manuscrite du cartulaire n'est pas négligeable depuis l'original entrepris au milieu du XIIIe siècle, conservé à Auxerre, jusqu'aux copies du XIXe siècle. Il n'a, en revanche, jamais été publié in extenso mais il en existe des éditions partielles publiées aux XIX et XX ${ }^{\mathrm{e}}$ siècles

Manuscrits

- Auxerre, B.M., ms. 161 G (anc. 142), Stein $n^{\circ} 286$.

- Paris, BnF, ms. fr. 18693 (p. 453-458), Stein n² 287. [Copie de six chartes présentes dans le cartulaire, réalisée au $\mathrm{XV}^{\mathrm{e}}$ siècle d'après les originaux]

- Auxerre, B.M., ms. 154 G (anc. 138), fo 219-228, dom Georges VIOLE, Historia abbatum monasterii sancti Germani Autissiodorensis, dans Mémoires sur l'histoire du diocèse d'Auxerre, Auxerre, vers 1640.

- AD Yonne, H 1010. [23 diplômes royaux copiés en 1670]

-Auxerre, B.M., ms. 163 G (anc. 144). [Abrégé des cartulaires de Saint-Germain par dom G. Ternat en $\left.1678, f^{\circ} 1-59\right]$

- Auxerre, B.M., coll. Bastard 294 (XXIV), fo 157-168. [Fragments copiés par le chartiste JeanDenis-Léon Bastard qui accumula de nombreuses fiches sur l'histoire auxerroise].

\section{Éditions partielles}

- J. LEBEUf, Mémoires concernant l'histoire civile et ecclésiastique d'Auxerre et de son ancien diocèse, 4 vol., 1743, réed. Auxerre-Paris, 1848-1855.

- Recueil des Historiens des Gaules et de la France, par les religieux et bénédictins de la congrégation de Saint-Maur, commencé par dom M. Bouquet, 1738-1904, t. VI, VIII-X.

- Gallia Christiana in provincias ecclesiasticas distributa..., t. XII (province ecclésiastique de Sens), Paris, 1770.

- M. QUANTIN, Cartulaire général de l'Yonne, 2 vol., Auxerre, 1854-1860. 
- M. QUANTIN, Recueil des pièces pour faire suite au cartulaire général de l'Yonne. XIII ${ }^{\mathrm{e}}$ siècle, Auxerre, 1873.

- Recueil des actes de Louis IV, roi de France (936-954), éd. Ph. LAUER, M. PROU (dir.), Paris, 1914.

- Recueil des actes de Charles III le Simple, roi de France (893-923), éd. Ph. LAUER, Ph. LOT (dir.), 2 vol., Paris, 1940-1949.

- Recueil des actes de Charles le Chauve roi de France (840-877), éd. A. GIRY, M. PROU, M. TESSIER, G. BRUNEL (dir.), 3 vol., Paris, 1955.

- Recueil des actes d'Eudes, roi de France (888-898), éd. G. TESSIER, R.-H. BAUTIER (dir.), Paris, 1967.

- Recueil des actes de Louis II le Bègue, Louis III et Carloman II rois de France (877-884), éd. J. de FONT-RÉAULX, F. GRAT, G. TESSIER, R.-H. BAUTIER, Paris, 1978.

Part des actes publiés

Comme le souligne le tableau ci-dessous, la proportion des actes du grand cartulaire aujourd'hui publiés est relativement faible (1/4). Si l'on excepte les diplômes royaux et impériaux dont la publication a été stimulée par le projet de la collection Chartes et diplômes relatifs à l'histoire de France, la part des actes restés inédits représente alors près de $80 \%$. Il convient aussi de souligner que l'attention des éditeurs s'est avant tout portée sur la première phase de rédaction du codex.

\begin{tabular}{|c|c|c|}
\hline \multicolumn{3}{|c|}{$\begin{array}{l}\text { GRAND CARTULAIRE de SAINT-GERMAIN } \\
\text { Actes édités }\end{array}$} \\
\hline $\begin{array}{l}\text { Privilèges pontificaux et } \\
\text { épiscopaux }\end{array}$ & $27 / 60$ & $45 \%$ \\
\hline Diplômes royaux et impériaux & $24 / 26$ & $92,3 \%$ \\
\hline $\begin{array}{l}\text { Actes concernant la cité } \\
\text { d'Auxerre et ses faubourgs }\end{array}$ & $9 / 50$ & $18 \%$ \\
\hline Actes concernant le doyenné & $16 / 34$ & $47 \%$ \\
\hline Actes concernant la chambre & $8 / 36$ & $22,2 \%$ \\
\hline Actes concernant le cellier & $7 / 28$ & $25 \%$ \\
\hline $\begin{array}{c}\text { Actes concernant Bercenay et } \\
\text { Vauchassis }\end{array}$ & $1 / 19$ & $5,2 \%$ \\
\hline
\end{tabular}

Un examen chronologique des actes édités met en évidence que les périodes les plus anciennes (IX ${ }^{\mathrm{e}}$-XII ${ }^{\mathrm{e}}$ siècle) sont celles qui ont le plus attiré l'attention des éditeurs. Cet attrait des périodes les plus hautes se retrouve dans l'état actuel de la publication des originaux du chartrier de Saint-Germain comme on peut le voir sur le tableau suivant. 


\begin{tabular}{|c|c|c|}
\hline \multicolumn{3}{|c|}{$\begin{array}{c}\text { Chartrier de Saint-Germain } \\
\text { Originaux conservés/édités }\end{array}$} \\
\hline & & dont édités \\
\hline IXe & 1 & $1(100 \%)$ \\
\hline Xe & - & - \\
\hline XIe & 2 & $2(100 \%)$ \\
\hline XIle & 6 & $5(83,3 \%)$ \\
\hline XIIle & 42 & $5(11,9 \%)$ \\
\hline XIVe & 13 & $-(0 \%)$ \\
\hline & & $13(20,3 \%)$ \\
\hline & Total $=64$ & \\
\hline
\end{tabular}

Quelques remarques sur les actes édités par Maximilien Quantin

Comme nombre de cartulaires de l'ouest de la Bourgogne ${ }^{2}$, celui de Saint-Germain n'a pas fait l'objet d'une édition complète. L'essentiel des actes publiés du grand cartulaire de Saint-Germain l'ont été par l'abbé Lebeuf au milieu du XVIII ${ }^{\mathrm{e}}$ siècle et surtout par l'archiviste de l'Yonne Maximilien Quantin un siècle plus tard.

Le projet de celui-ci dépassait un intérêt précis pour un établissement. Loin de limiter ses recherches à l'horizon restreint d'un cartulaire spécifique, il entreprit de réunir en un grand Cartulaire général de l'Yonne tous les actes susceptibles d'éclairer l'histoire d'une région qui, selon ses propos en introduction à son travail, « des premiers siècles de la monarchie jusqu'au XII ${ }^{e}$ siècle [...] a été soumise à des autorités très diverses » (p. IV). Aussi ne se chargea-t-il pas de donner une transcription intégrale des manuscrits concernés mais préféra-t-il publier un recueil de " morceaux choisis ».

Pour essayer de cerner la méthode de l'archiviste que fut Quantin, la base de l'enquête s'est appuyée sur les 83 actes du Grand cartulaire de Saint-Germain qu'il a publié dans les trois volumes de son ouvrage. Comme il le dit lui-même en introduction à son premier volume (p. V), Quantin indique en tête de la liste des sources qu'il donne pour chaque texte, le document qui lui a servi de référence pour l'établissement de son édition. À partir de là, on peut dresser un tableau des sources qu'il a utilisé et faire un certain nombre de remarques sur sa méthode de travail.

\begin{tabular}{|c|c|}
\hline $\begin{array}{c}\text { Sources utilisées par M. Quantin pour établir son édition } \\
\text { des actes du grand cartulaire }\end{array}$ \\
\hline Originaux & 5 \\
\hline Grand cartulaire & 63 \\
\hline dom G. Viole & 2 \\
\hline Gallia Christiana & 1 \\
\hline RHGF & 12 \\
\hline & Total $=83$ \\
\hline
\end{tabular}

- La méthode de Quantin n'est pas de s'appuyer systématiquement sur les originaux. Neuf des actes du Grand cartulaire qu'il a édités sont conservés en original, il n'en utilise que cinq, sans toujours mentionner d'ailleurs leur présence dans le cartulaire. Pour trois autres l'existence d'un original n'est pas indiquée, et enfin pour le dernier, il mentionne l'original sans l'utiliser. Il semble donc que Quantin n'instaure pas ici de hiérarchie entre les actes, notamment entre original et copie. La chronologie des copies n'est pas non plus à ses yeux un critère discriminant.

- Il lui arrive aussi de préférer des copies modernes manuscrites comme celles transcrites par dom Georges Viole vers 1640 dans ses Mémoires sur l'histoire du diocèse d'Auxerre, sans pour autant justifier son choix d'autant que Dom Viole n'indique pas ses sources. Même si l'on sait 
que celui-ci avait à sa disposition des originaux aujourd'hui disparus, on ne peut affirmer que Quantin choisissait dom Viole parce qu'il estimait que sa leçon était la meilleure.

- Quantin reprend aussi des éditions du XVIII ${ }^{\mathrm{e}}$ siècle -Gallia Christiana, Recueil des historiens des Gaules et de la France- qu'il rectifie parfois après collation sur le Grand cartulaire. Là aussi, il est difficile de cerner les motivations qui président à la préférence donnée à ces éditions plutôt qu'aux copies du cartulaire.

- 1 convient aussi de souligner une certaine évolution de la méthode de Quantin entre les différents volumes parus à près de vingt d'intervalle : 1854-1873. Le Recueil des Historiens des Gaules, la Gallia Christiana et dom Viole ne sont utilisés que dans le $1^{\mathrm{er}}$ volume pour les actes qui nous concernent. Dans les deux autres volumes les actes sont établis à partir du grand cartulaire ou à partir des originaux.

- Terminons sur la qualité des transcriptions proposées. Si l'on excepte la modification systématique ou fréquente des certaines graphies (u modifié en v ; ac modifié en et), il faut souligner que les erreurs d'établissement du texte sont assez marginales.

Table des actes du grand cartulaire de Saint-Germain d'Auxerre ${ }^{3}$ (Auxerre, B.M., ms. 161 $\mathrm{g}$ [anc. 142])INCIPIUNT CAPITULA OPERIS SEQUENTIS ET PRIMO PRIUILEGIA A SUMMIS PONTIFICIBUS CONCESSA.

[1] I- De protectione monasterii nostri et confirmacione prioratuum et ecclesiarum et aliarum rerum ${ }^{4}$. [9 février 1152, Eugène III] fo $8-8 v^{\circ}$

21 [2] II- De confirmacione et protectione sicut primum et libera sepultura monasterii nostri ${ }^{5}$. [25 février 1154, Anastase IV] fo $8 v^{\circ}-9$

[3] III- De confirmacione et proteccione in omnibus sicut primum et secundum necnon et libera sepultura monasterii nostri. [30 avril 1155, Adrien IV] fo9-9v ${ }^{\circ}$

[4] IIII- De confirmacione prioratuum et ecclesiarum et villarum nostrarum et ne soluatur emenda pro absolucione excommunicatorum ${ }^{6}$. [7 mai 1188, Clément III] $f^{\circ} 9 v^{\circ}-10 v^{\circ}$

[5] V- Item de confirmacione prioratuum et ecclesiarum et uillarum nostrarum et ne soluatur emenda pro absolucione ${ }^{7}$. [16 juillet 1194 , Célestin III] fo $10 v^{\circ}-11 v^{\circ}$

[6] VI- Item de confirmacione prioratuum et rerum aliarum in omnibus sicut quartum et quintum ${ }^{8}$. [18 juin 1198 , Innocent III] $f^{\circ} 11 v^{\circ}-13$

[7] VII- De remouenda parua consuetudine ecclesie nostre multum nociua9 ${ }^{9}$ [8 avril 1156, Adrien IV] fo 13

[8] VIII- Ne episcopus Autissiodorensis nos uel presbiteros uel homines nostros possit excommunicare sine causa racionabili et iuris ordine obseruato ${ }^{10}$. [26 août 1186, Urbain III] $f^{\circ} 13-13 v^{\circ}$

28 [9] IX- Item de eodem ne episcopus Autissiodorensis ut contra ut supra in proximo. [22 juin 1194 , Célestin III] f $13 v^{\circ}$

[10] X- Ne episcopus Autissiodorensis uel presbyteri homines nostros excommunicent sine manifesta et racionabili causa et iuris ordine obseruato. Alioquin sententia non teneat et nos eis diuina celebremus. [12 juillet 1194, Célestin III] $f^{\circ} 13 v^{\circ}$

[11] XI- Item de eodem uerbo ad uerbum. [16 mai 1198, Innocent III] fo13 $v^{\circ}$

31

[12] XII- De benedictionibus, ordinacionibus, consecracionibus et ne homines nostri persoluant pecuniam pro absolucione excommunicationis optinenda ${ }^{11}$. [4 juin [1186], Urbain III] $f^{\circ} 13 v^{\circ}$ 
[13] XIII- Item de eodem verbo ad uerbum. [27 juin 1194, Célestin III] $f^{\circ} 13 v^{\circ}$

[14] XIIII- Item de eodem uerbo ad uerbum. [16 mai 1198, Innocent III] fo $13 v^{\circ}-14$

[15] XV- Ne episcopus uel eius officialis vel alius possit extorquere pecuniam ab hominibus nostris pro contumacia ${ }^{12}$. [ 25 février 1253, Innocent IV] f ${ }^{\circ} 14$

[16] XVI- Quere literam conseruatoriam post negocium Cluniacensem. Item quod episcopi et archidiaconi contenti sint numero familiarum et equorum que continentur in concilio Laterani ${ }^{13}$. [11 mai 1186, Urbain III] $f^{\circ} 14$

[17] XVII- De eodem verbo ad verbum. [25 juin 1194, Célestin III] fo14

[18] XVIII- Quod possumus saisire temporalia in ecclesiis nostris nisi presbyteri ueniant ad citacionem abbatis ${ }^{14}$. [16 juillet 1194, Célestin III] fo $14-14 v^{\circ}$

[19] XIX- Ut presbyteri ecclesiarum nostrarum coram abbate de temporalibus

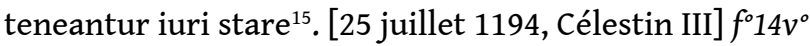

[20] XX- Ut dimisso episcopo Autissiodorensis si fuerit negligens adeamus archiepiscopum Senonensem ad prosequendam iusticiam ${ }^{16}$. [25 juin 1194, Célestin III] $f^{\circ} 14 v^{\circ}$

[21] XXI- Ut ubi percepimus ueteres decimas percipiamus et nouas de terris nouiter ad culturam redactis ${ }^{17}$. [18 décembre $1227-1228$, Grégoire IX] f $f^{\circ} 14 v^{\circ}$

[22] XXII- De eodem ${ }^{18}$. [9 avril 1255-1256, Alexandre IV] $f^{\circ} 14 v^{\circ}$

[23] XXIII- Ne de noualibus nostris seu nutrimentis animalium decimas exsoluamus ${ }^{19}$.

[17 janvier 1199-1200, Innocent III] f $f^{\circ} 14 v^{\circ}-15$

[24] XXIIII- Item de eodem ${ }^{20}$. [9 avril 1255-1256, Alexandre IV] fo 15

[25] XXV- De quibusdam decimis iuxta Seliniacum. [7 mai 1198, Innocent III] fo 15

[26] XXVI- Quod possumus subtrahere hoc quod debemus canonicis sancti Stephani nisi ueniant ad processiones statutas ${ }^{21}$. [9 juillet 1195, Célestin III] $f^{\circ} 15$

[27] XXVII- Ne id quod sit a nobis ex curialitate possit imposterum exigi de consuetudine. [3 août 1254, Alexandre IV] fo $15-15 v^{\circ}$

[28] XXVIII- Quod non tenemur alicui prouidere in pensionibus uel ecclesiasticis beneficiis ${ }^{22}$. [27 février 1254, Alexandre IV] f $f^{\circ} 15 v^{\circ}$

[29] XXIX - De libera sepultura tempore generalis interdicti ${ }^{23}$. [23 juillet 1254 , Alexandre IV] $f^{\circ} 15 v^{\circ}$

[30] XXX- De prioratu sancti Florentini et de amonicione canonicorum et institutione monachorum ${ }^{24}$. [24 mars 1138, Innocent II] fo $15 v^{\circ}-16$

[31] XXXI- De libertate cellarii de sancto Florentino et augmentacione nundinarum ${ }^{25}$. [27 juin 1190, Clément III] fo16

1 [32] XXXII- De ecclesia de Heruiaco ${ }^{26}$. [1er février 1177, Alexandre III] f ${ }^{\circ} 16$

[33] XXXIII- De confirmacione prefate ecclesie ${ }^{27}$. [27 juin 1194, Célestin III] fo16

[34] XXXIIII- De ecclesia de Heruiaco, de monasterio Heraudi et de iure patronatus ${ }^{28}$. [1er juin 1186, Urbain III] f $f^{\circ} 16-16 v^{\circ}$

[35] XXXV- De libera sepultura Disesie ${ }^{29}$. [21 août [1186], Urbain III] fo $16 v^{\circ}$

[36] XXXVI- De eodem ${ }^{30}$. [18 juin 1194, Célestin III] f $16 v^{\circ}$

[37] XXXVII- De ecclesiis de Breceniaco et Vaucharci in episcopatu Trecensi ${ }^{31}$. [27 juin 1194, Célestin III] fo $16 v^{\circ}$ 


\section{$f^{\circ} 19-19 v^{\circ}$}

70 [51] LI- Confirmacio sententie predicte facta a domino Alexandro papa quarto ${ }^{43}$. [31 mars 1256] fo $19 v^{\circ}-20$

71 [52] LII- Litera domini Ricardi cardinalis testimonialis de reddendis scriptis qui nos tangerunt ecclesiam nostram. [30 mars 1256] fo 20

72 [53] LIII- Item alia littera eiusdem cardinalis de reddendis eisdem scriptis ${ }^{44}$. [5 avril 1256] fo 20

73 [54] [LIIII- Litera sequens tenet locum post quintum decimum priuilegium antecedens, et est litera conseruatoria ipsius priuilegii videlicet Innocencii IV pape quod homines nostri nichil soluant pro contumacia sicut nec pro absolucione excommunicacionis ${ }^{45}$. [7 mars 1253, Innocent IV] fo $20-20 v^{\circ}$

74 [55]- [Honorius papa quartus nequis absque iuris ordine audeat occupare bona ecclesiae nostre Vadiare detinere vel molestias nobis inferre ${ }^{46}$. [29 septembre 1285, Honorius IV] $f^{\circ} 20 v^{\circ}-21$

75 [56]- [Honorius papa quartus, ut de cetero possimus uti priuilegiis nostris quamquam usi non fuimus per simpliciter iure et ignoranter temporibus retroactis]. [29 septembre 1285, Honorius IV] f 21 
[57]- Confimacio omnium priuilegium nobis concessorum. [29 septembre 1285 Honorius IV] $f^{\circ} 21$

[58]- [Honorius papa quartus, ut bona omnia que fratres et professos nostros ratione successoris vel alio iusto titulo contingeret pete et recipere valeamus]. [29 septembre 1285 , Honorius IV] $f^{\circ} 21-21 v^{\circ}$

[59]-Confirmacio priuilegiorum. [29 septembre 1285, Honorius IV] f $21 v^{\circ}$

[60]- Bulla de pictanciis priorum ${ }^{47}$. [1er mai 1370, Urbain V] $f^{\circ} 21 v^{\circ}-23 v^{\circ}$ INCIPIUNT CARTE REGUM ET IMPERATORUM.

[61] I- Preceptum Karoli imperatoris de rebus quas dedit Adelbertus in Riuisiaco et Sarmasia $^{48}$. [7 mai 877] fo24

[62] II- Ludouicus imperator de electione abbatum et de eodem quinta litera sequens facit mencionem ${ }^{49}$. [29 juillet 835] f $24-24 v^{\circ}$

[63] III- Karolus rex de custodia et proteccione omnium rerum nostrarum ${ }^{50}$. [11 septembre 859] $f^{\circ} 24 v^{\circ}-25$

[64] IIII- Item Karolus rex de translacione corporis sancti Germani de villa que dicitur Modolagium $^{51}$. [9 janvier 859] fo25

[65] V- Karolus rex de restitucione Modolagii ad usus et stipendium monachorum ${ }^{52}$. [11 octobre 861] fo $25-25 v^{\circ}$

[66] VI- Karolus rex de commutacionibus Riconori et Modolagii ${ }^{53}$. [2 décembre 863] $f^{\circ} 25 v^{\circ}$

[67] VII- Ludouicus rex de collacione Modolagiii ${ }^{54}$. [29 janvier 878] fo $25 v^{\circ}-26$

[68] VIII- Karolus rex de Irenciaco et rebus aliis ${ }^{55}$. [22 avril 900 ou 901] fo26

[69] IX- Karolus rex de quibusdam uillis usibus monachorum concessis ${ }^{56}$. [30 juin 853] $f^{\circ} 26-26 v^{\circ}$

[70] X- Karolus rex de quibusdam rebus ordinacis ad luminaria ecclesie et benedictionem fratrum ${ }^{57}$. [11 septembre 859] $f^{\circ} 26 v^{\circ}-27$

[71] XI- Karolus rex de quadam uinea infra fines Vincelli concessa ad usus monachorum $^{58}$. [14 septembre 861] $f^{\circ} 27$

1 [72] XII- Karolus rex de quibusdam rebus in uilla que dicitur Sidiliacus ${ }^{59}$. [18 janvier 863 ou 864] fo $27-27 v^{\circ}$

[73] XIII- Karolus rex de quadam uilla que dicitur Berniacus ${ }^{60}$. [23 janvier 866] fo $27 v^{\circ}-28$

[74] XIIII- Karlomagnus de quibusdam rebus datis cuidam capellano nomine Arueo ${ }^{61}$ [880-881] fo $28-28 \mathrm{v}^{\circ}$

[75] XV-Carta Hugonis atque Roberti regum Francie de eleccione abbatem et ecclesia Sancti Leodegarii ${ }^{62}$. [11 octobre 994] $f^{\circ} 28 v^{\circ}$

5 [76] XVI- Karolus rex de plenaria proteccione rerum et libertatum et de quitacione thelonei et aliis ${ }^{63}$. [11 septembre 859] fo $28 v^{\circ}-29$

96 [77] XVII- Karolus rex de villis nostris et de commutacione quarumdem uillarum et rebus aliis ${ }^{64}$. [20 juin 864$] f^{\circ} 30-30 v^{\circ}$

[78] XVIII- Karlomannus rex de villis, de quibusdam prioratibus nostris, de quitacione thelonei, de tuicione et excludenda episcoporum et ministrorum seu aliorum iudicium potestate $^{65}$. [11 juin 884] fo $30 v^{\circ}-32$ 

tuicione et aliis ${ }^{66}$. [28 octobre 886] f f $^{\circ} 2-33$ [11 juillet 889 ] f $33-33 v^{\circ}$ [1002-1010] fo $35 v^{\circ}-36$ et dimidio et de redditu XV denarios. [janvier 1210] fo 36 ou 817] f $36 v^{\circ}$ collatorum $^{72}$. [après le 20 juin 864 ] fo37-38 AUTISSIODORI ET CIRCA EANDEM CIUITATEM. [1121-1122] fo 40 faciendos. [1193] $f^{\circ} 40 v^{\circ}$ aliis $^{74}$. [1148] $f^{\circ} 40 v^{\circ}$

[90] IIII- Carta de empcione quatuor fratrum ${ }^{75}$. [1152-1161] fo $40 v^{\circ}-41$

[91] V- De quodam homine vocato bibe sanitatem ${ }^{76}$. [1159] fo 41

[92] VI- De gistagio et herbergagio apud Orgiacum. [1210] $f^{\circ} 41$

[93] VII- Item de eodem. [1210] $f^{\circ} 41$ [février 1238] f $41 v^{\circ}$

[96] X-Carta episcopi Meldensi de eodem ${ }^{78}$. [février 1238] f $^{\circ} 41 v^{\circ}$

[97] XI- De molendino de Orgiaco. [1167-1220] fo $41 v^{\circ}$

[98] XII- De casamento Gilonis militis ${ }^{79}$. [1142-1168] fo $41 v^{\circ}-42$ [mars 1230] f 42

[100] XIIII- De eodem.[mars 1230] fo $42-42 v^{\circ}$ [janvier 1237] $f^{\circ} 42 v^{\circ}$

[79] XIX- Karolus imperator de villis nostris, prioratibus, de quitacione thelonei, de

[80] XX- Odo rex de plenissima protectione et defensione omnium rerum nostrarum ${ }^{67}$.

[81] XXI- Odo rex de villis nostris et prioratibus et quadam commutacione, de protectione, de quitacione thelonei et rebus aliis ${ }^{68}$. [11 juillet 889] f $f^{\circ} 33 v^{\circ}-35$

[82] XXII- Ludouicus rex de defensione et protectione, de excludenda episcoporum et aliorum potestate de quitacione thelonei et rebus aliis ${ }^{69}$. [26 juillet 936] $f^{\circ} 35-35 v^{\circ}$

[83] XXIII- Rotbertus rex de plenissima defensione et gubernacione, de thelonei quitacione, de excludenda episcoporum et aliorum potestate, oblacione et eleccione ${ }^{70}$.

[84] XXIIII- Carta Ludouici primogeniti regis francorum de duobus arpentis plantarum

[85] XXV- De quatuor nauibus super ligerim et aliis fluminibus necnon et theloneo et aliis diuersis libertatibus et habet locum post primam literam de regibus ${ }^{71}$. [10 mars 816

[86]-Privilegium episcoporum siue confirmatio bonorum regiam munificenciam

INCIPIUNT SCRIPTA ET MUNIMENTA DE BONIS QUE HABEMUS IN CIUITATE

[87] I- De libertatibus nostris in castro et burgo sancti Germani Autissiodorensis ${ }^{73}$.

[88] II- Quod nos seu homines nostri non tenemus adiuuare ad muros ciuitatis

[89] III- Carta Iterii de Melliniaco et Johannis de Chasellis de quodam censu et rebus

[94] VIII- De empcione medietatis uille de sancto Georgio. [février 1238] fo $41-41 v^{\circ}$

[95] IX-De laudacione vendicionis facte apud Perriniacum et sanctum Georgium ${ }^{77}$.

[99] XIII- De quitacione gisti et herbergagii apud Parrigniacum et sanctum Georgium.

[101] XV- De donacione rerum quas Johannes de Barris habuit apud Perrigniacum.

21 [102] XVI- De quatuor arpentis plantarum et uno arpento vinee. [1210] $f^{\circ} 42 v^{\circ}$ 
[103] XVII- Item de quinque arpentis vinee. [janvier 1237] $f^{\circ} 42 v^{\circ}$

[104] XVIII- De quadam obligacione nobis facta ab abbate et conuentu Verzeliacensis. [1210] $f^{\circ} 42 v^{\circ}-43$

[105] XIX- De domibus contiguis ecclesie sancti Lupi. [s.d.] fo43

[106] XX- De arbitrio inter nos et dominum Petrum de Orto super medietate aque iuxta molendina de Scale et super Insulis. [1215] fo43

[107] XXI- De quitacione et uendicione quatuor modiorum uini nobis facta ${ }^{80}$. [février 1226] $f^{\circ} 43$

[108] XXII- De laudacione prefate vendicionis. [mars 1226] fo $43-43 v^{\circ}$

[109] XXIII- De compromissione facta inter nos et canonicos sancti Stephani de hostiis clausis in processionibus ${ }^{81}$. [janvier 1242] fo $43 v^{\circ}-44$

[110] XXIIII- Arbitrium pronunciatum super premissis.[février 1242] fo44-44v ${ }^{\circ}$

[111] XXV- Litere de XL solidos super domos Odonis Berbiete ad matutinum domine nostre. [mer. 28 septembre 1250] f $f^{\circ} 4 v^{\circ}-45 v^{\circ}$

[112] XXVI- De vendicione predictarum domorum Odonis Barbiete. [août 1265] fo $45 v^{\circ}$

[113] XXVII- De plenaria vendicione et quitacione predictarum domorum. [avril 1266] $f^{\circ} 45 v^{\circ}-46$

[114] XXVIII- De feodo quod tenet dominus Petrus de Mers ab abbate Sancti Germani. [1er décembre 1249] f०46

4 [115] XXIX- De vinea de Bruilat et quadam alia nobis uendita. [24 décembre 1256] $f^{\circ} 46-46 v^{\circ}$

[116] XXX- De tenemento Macignons de Parrigniaco. [5 janvier 1256] $f^{\circ} 46 v^{\circ}$

[117] XXXI- Carta domini Petri comitis Nivernensis de magna Brueria et de Monbolon et de forestariis et forefactis ${ }^{82}$. [1187] $f^{\circ} 46 v^{\circ}-47$

[118] XXXII- Carta eiusdem de eodem et de donacione facta domino Droconi de Merloto $^{83}$. [1198] f० $47-47 v^{\circ}$

8 [119] XXXIII- Item carta eiusdem comitem de eadem donacionem. [1198] fo $47 v^{\circ}$

[120] XXXIIII- Carta domini Droconis de Merloto de eisdem nemoribus et aliis conuencionibus. [janvier 1201] f $47 v^{\circ}$

[121] XXXV- Carta domini Droconis de composicione inter nos et ipsum facta ${ }^{84}$. [1203] $f^{\circ} 48$

[122] XXXVI- Litera capituli Autisiodorensis de compromissio facto super pastura nemoris de Brueria ${ }^{85}$. [mai 1243] fo 48

[123] XXXVII- Item ut in nemore predicto non pasturent animalia capituli nisi post tertium folium ${ }^{86}$. [septembre 1243] $f^{\circ} 48-48 v^{\circ}$

[124] XXXVIII- De quibusdam querelis inter nos et conuentum Sancti Mariani per amicabilem composicionem sedatis et terminatis ${ }^{87}$. [1212] $f^{\circ} 48 v^{\circ}-49$

[125]- Sentencia officialis Autissiodorensis contra curatus de Sancta Columba ${ }^{88}$. [3 février 1288] f०49

[126]- Promisis ipsius curati Sanctae Columbae ${ }^{89}$. [7 février 1288] f०49

[127]- Donatis duorum molinarum vini et quitatio aliorum duorum. [Janvier 1226] $f^{\circ} 49-49 v^{\circ}$ 
[128]- Jus patronatus curie de Lanniis et de Carisiaci ad abbatem sancti Germani pertinet. [28 août 1286] fo $49 v^{\circ}$

[129]- Jus patronatus curia de Annaio super riuariam ad nos pertinet. [1292] fo $49 v^{\circ}$

[130]- Monachorum sancti Mariani voluntas pro literas nobis necessariis in eorum monasteriorum inspectis ad usum nostrum. [1291] f $49 v^{\circ}-50$

[131]- Vendition de la tierce partie dune place sise au bourg Saint Loup. [mer.15 décembre 1300] fo50-51

[132]- Vendition dune autre tierce partie sise au bourg Saint Loup.[15 novembre 1300] $f^{\circ} 51-51 v^{\circ}$

[133]- Vendition de la neufviesme partie de la dite place. [15 novembre 1300] fo51 $v^{\circ}-52$

[134]- Place Saint Loup, petite rue St-Germain [2 novembre 1300] f $52 v^{\circ}-53$

[135]- Carta nova abbatis et conuentus monasterii Sancti Germani Autissiodorensis et domini Droconis de Melloto super diuersis articulis et debet esse post XXXV supra verte quinque folia. [octobre 1289] f $53-54$

[136]- Lettre declarative du duc Philippe pour montrer que la taille quil a levee sur les terres de leglise ne leur permet prejudice. [17 août 1436] fo54 INCIPIUNT LITERE DE DECANIA.

[137] I- Quitacio Renaudi de Narbona et filiorum eius de siluis et nemoribus prope Digiam $^{90}$. [1142] fo55

[138] II- Carta episcopi Autissiodorensis et Gaufridi Donziaci pro saluamento noui burgi de Digia $^{91}$. [1151] fo $55-55 v^{\circ}$

[139] III- Carta Willelmi comitis de Digia, de Villa noua et de LX solidis datis ad anniuersarium $^{92}$. [1161] $f^{\circ} 55 v^{\circ}$

[140] IIII- Carta Willelmi comitis Nivernensis, de terre de Digia, de aiis, de herbergamento, de burgo Sancti Germani ${ }^{93}$. [1165] f $55 v^{\circ}$

[141] V- Carta Guidonis comitis Nivernensis, de Willelmo de Monte Marcii et fratre eius et uxore Garnerii, datis ecclesie nostre ${ }^{94}$. [1171] $f^{\circ} 55 v^{\circ}-56$

[142] VI- Carta eiusdem comitem de saluamento Digie et de Escanz et de arbergagio Digie et de villa noua ${ }^{95}$. [1171] fo56

[143] VII- Carta eiusdem comititis de inuadacione herbergagii de Eschanz. [1175] $f^{\circ} 56-56 v^{\circ}$

[144] VIII- Carta Willelmus Autisiodorensis episcopus de predicta inuadacione herbergagii de Eschanz. [vers 1175] fo56v ${ }^{\circ}$

[145] IX- Quitacio Guidonis comitis de herbergagio in potestate de Escanno et de Similiaco $^{96}$. [1175] $f^{\circ} 56 v^{\circ}$

[146] X- Quitacio comitisse de Bolonia de saluamento de Digia ${ }^{97}$. [1175] $f^{\circ} 56 v^{\circ}-57$

[147] XI- De tribus modiis auene datis P. comitis Niuernensis pro saluamento terre de Digia. [1185] fo57

[148] XII- Carta Willelmi comitis Niuernensis de quibusdam consuetudinibus in Digia et Escanno ${ }^{98}$. [1148-1161] $f^{\circ} 57$

[149] XIII- Item de saluamento et herbergagio in Digia et in potestate eius ${ }^{99}$. [1201] fo57 
[150] XIIII- Item de saluamento et herbergagio in burgo et potestate Digie. [novembre $1201] f^{\circ} 57-57 v^{\circ}$

[151] XV- De quadam decima apud Berneium ${ }^{100} \cdot[1210] f^{\circ} 57 v^{\circ}$

[152] XVI- De domo contigua ecclesie de Eschanz. [1210] fo57v $v^{\circ}$

[153] XVII- De vendicione facta a Jocelino de Marnaio de hiis que habuit in Digia. [1211] fo $57 v^{\circ}$

[154] XVIII- Quitacio Humbaudi Fillons de Ebrardo de Cereno et heredibus suis ${ }^{101}$. [décembre 1214] f $57 v^{\circ}$

[155] XIX- Carta de hiis que Petrus de Bruilet et G. frater eius habuerunt in potestate Digie. [juillet 1218] $f^{\circ} 57 v^{\circ}-58$

[156] XX- De Herueo celerario de Digia ${ }^{102}$. [décembre 1218] fo58

[157] XXI- De quadam obligacione nobis facta a Rainaudo filio Stephani Morelli de Digia $^{103}$. [février 1218] f 58

[158] XXII- Item de quitacione Ebrardi de Cereno. [juillet 1219] fo58

[159] XXIII- De censu nobis soluendo de domo curati de Digia. [1242] fo58

[160] XXIIII- Compromissio de consuetudine que dicitur melicia inter nos et episcopum Autisiodorum ${ }^{104}$. [1220] $f^{\circ} 58 v^{\circ}$

[161] XXV-Item alia compromissio de eodem. [1220] fo58v

[162] XXVI-105

[163] XXVII- Item compromissio de predicta consuetudine et aliis exaccionibus inter nos et episcopum. [mars 1224] fo58v ${ }^{\circ}-59$

[164] XXVIII- Hic scribatur arbitrium precedentis compromissi si inueniatus ${ }^{106}$. [novembre 1284] fo59

[165] XXIX- De porcionibus nostris in ecclesia de Eschanno. [janvier 1239] $f^{\circ} 59 v^{\circ}$

[166] XXX- Item de predictis porcionibus oblacionum ad firma traditis pro quatuor libris turonensis. [janvier 1239] f $59 v^{\circ}$

[167] XXXI- Quitacio nobis facta de Narduino dicto Corneaul et liberis ac heredibus eius. [juin 1247] fo59v $\mathrm{v}^{\circ}-60$

[168] XXXII- Carta abbatis et conventus de molendino de Villeta domui de Bello Monte tradita $^{107}$. [avril 1233-1234] f $f^{\circ} 00$

[169]- Vendites de celerarie de Digia. [août 1247] fo60

[170]- De oblationibus habere debemus in ecclesia de Digia. [1259] fo60-60v ${ }^{\circ}$

[171]- De sex solidis et octo denariis novis debitis in finagio de Villari. [1271] f $60 v^{\circ}-61$ INCIPIUNT SCRIPTA DE CAMERA.

[172] I- Conuencio inter ecclesiam nostram et ecclesiam Pontigniacensi de molendino dicto Spaillard ${ }^{108}$. [1133] $f^{\circ} 61 v^{\circ}$

[173] II- De Justicia Gurgiaci, de saluamento, de libertatibus et aliis consuetudinibus ipsius $^{109}$. [1165] $f^{\circ} 61 v^{\circ}-62$

3 [174] III- De impignoracione omnium rerum quas Johannes vicecomes Lagniaci habuit in Roureto ${ }^{110}$. [1165] f 62

[175] IIII- De anniuersario Petrus Phalordiax. [s.d.] fo62 
[176] V- De quadam controuersia inter nos et Pontigniacenses per arbitros determinata ${ }^{111}$. [1192] f $f^{\circ} 62-62 v^{\circ}$

[177] VI- De pastinagio porcorum in nemore de Riuisiaco et aliis controuersiis et querelis inter nos et Pontiniacenses similiter determinatis. [novembre 1230] $f^{\circ} 62 v^{\circ}-63$

[178] VII- De compromissione facta inter nos et Pontigniacenses super nemore de Riuisiaco ${ }^{112}$. [août 1231] fo $63-63 v^{\circ}$

[179] VIII- Item alia compromissio inter nos et Pontigniacenses de predicto nemore de Riuisiaco. [décembre 1232] f $63 v^{\circ}$

[180] IX- Item alia compromissio inter nos et eosdem super diuersis articulis. [septembre 1234] f ${ }^{\circ} 63 v^{\circ}$

[181] X- Item compromissio facta inter nos et Pontigniacenses super diuersis articulis. [13 juin 1235] fo $63 v^{\circ}-64$

[182] XI- Arbitrium cantoris Autissiodorensis et decani Tornodorensi super diuersis querelis et controuersis inter nos et pontiniacenses per arbitrium terminatis ${ }^{113}$. [mai 1238] fo64-65

[183] XII- Litere archidiaconi Autissiodorensis super arbitrio cantoris Autissiodorensis et decani Tornodorensis inter nos et Pontiniacenses ${ }^{114}$. [février 1240] f ${ }^{\circ} 65-65 v^{\circ}$

[184] XIII- Litera non est hic ${ }^{115}$.

[185] XIIII- De quitacione hominum et mulierum domini Willelmi de Booliaco militis. [février 1226] f $65 v^{\circ}$

[186] XV- De forestariis apud Eriacum nouitur receptis que tenentur dare plegiosus ad exequendum fideliter officium suum. [février 1233] f ${ }^{\circ} 65 v^{\circ}$

[187] XVI- De amicabili composicione inter abbatem et Iobertum dominum de Venossa super iusticia in Roureto. [octobre 1233] f ${ }^{\circ} 65 v^{\circ}-66$

[188] XVII- Item de amicabili composicione inter abbatem et predictum Jobertum super predictis $^{116}$. [octobre 1233] fo66-67

[189] XVIII- De donacione rerum quas Johanna vicecomitissa de Legniaco castro habuit in Roureto. [octobre 1231] f 67

[190] XIX- Item de donacione rerum quas Regina Ferdeal et Johannes maritus eius habuerunt in Roureto. [décembre 1234] fo67

[191] XX- De quadam placea in Heriaco nobis collata. [1211] fo67

[192] XXI- De quitacione decimarum de Saliceto de subtus Chimili. [s.d.] fo67-67v ${ }^{\circ}$

[193] XXII- De donacione Elisabeth uxoris Laurentii de Gurgiaco et heredum ipsius. [mars 1231] f $67 v^{\circ}$

3 [194] XXIII- De escambio facto pro Stephano Copin et heredum eius ${ }^{117}$. [juillet 1234] $f^{\circ} 67 v^{\circ}$

4 [195] XXIIII- De conuencione inter nos et capitulum Autissiodorum de quadam placea in Roureio. [juillet 1245] $f^{\circ} 67 v^{\circ}$

5 [196] XXV- De porcionibus oblacionum nostrarum in ecclesia de Roureto ${ }^{118}$. [mars 1255] $f^{\circ} 67 v^{\circ}-68$

16 [197] XXVI- De quadam composicione facta inter nos et Vitalem le Sac. [mars 1259] fo68 
[198] XXVII- De quadam compromissione facta inter nos et dominum de Selleniaco. [11 et 25 mars 1222$] f^{\circ} 68-68 v^{\circ}$

[199] XXVIII- Carta domini Stephani de Selliniaco de iusticia, forestariis, forefactis, nemoribus, diuisionibus terrarum et aliis ${ }^{119}$. [1228] $f^{\circ} 68 v^{\circ}-70$

[200] XXIX- De vendicione tercium modiorum auene nobis facta a domino de Selliniaco. [juillet 1238] fo 70

[201] XXX- Litera decani Autissiodorensis de predicta vendicione tercium modiorum auene. [juillet 1238] fo $70-70 v^{\circ}$

[202] XXXI- Item de eadem vendicione. [juillet 1238] $f^{\circ} 70 v^{\circ}$

[203] XXXII- De quadam obligacione nobis facta a Stephano domino de Selliniaco. [juillet 1238] $f^{\circ} 70 v^{\circ}$

[204] XXXIII- Quitacio domini Colini de Castellione militis de predictis tribus modiis auene. [août 1238] fo $70 v^{\circ}-71$

[205] XXXIIII- De diuisione nemoris quod dicitur Salicetum et illius que dicitur Brocia Galteri inter nos et dominum Selliniacum. [avril 1248] f०71

[206] XXXV- De hospicio magistri Alberti notarii apud Eriacum. [6 décembre 1254] fo71

[207]- Littera officialis Brinonensis de quitacione liberorum Ribaldau de Ulmeto ${ }^{120}$. [11 février 1270] f $71 v^{\circ}$

[208]- Carta inter nos et heredes de Seillenay quod hii que tenebunt de rebus communis societatis tenentur facere juramentum et fidelitatem ecclesie nostre in capitulo et super aliis articulis. [8 avril 1275] $f^{\circ} 71 v^{\circ}-72 / 77-77 v^{\circ}$

SCRIPTA DE CELARIO.

[209] I - De empcione duorum hominum apud villam de Veneto ${ }^{121}$. [1155-1160] $f^{\circ} 72 v^{\circ}$

[210] II- De capella in bosco de Beletano constructa in parrochia de Venneio. [s.d.] f $72 v^{\circ}$

[211] III- De rebus quas Herbertus Ricardus habuit in dominio apud Blaaniacum. [1146] $f^{\circ} 72 v^{\circ}$

[212] IIII- De duobus modiis vini nomine decime nobis a fratribus de Regneio annuatim soluendis ${ }^{122}$. [1169] $f^{\circ} 72 v^{\circ}$

[213] V- De decimis quas habemus in Venneto, in Blegniaco, in Baina ${ }^{123}$. [1169] fo $72 v^{\circ}-73$

[214] VI- De quinquaginta solidis in ecclesia de Blagniaco annuatim percipiendis ${ }^{124}$. [s.d.] f $f^{\circ} 73$

[215] VII- De gageria rerum quas Herbertus de Marri habuit in territorio et potestate de Hirenciaco ${ }^{125}$. [s.d.] fo73

[216] VIII- De medietate nemoris quod dicitur Vairau et forestariis et forefactis et aliis $^{126}$. [1196] fo $73-73 v^{\circ}$

[217] IX- De plantis molendini de Riueta. [1198] $f^{\circ} 73 v^{\circ}-74$

[218] X- Item de eisdem plantis. [1202] fo74

[219] XI- De admodiacione rerum quas habemus in parrochia de Lignerolis et de Veyli. [octobre 1214] f $f^{\circ} 74$

[220] XII- De porcionibus nostris in ecclesia de Ligneroliis ${ }^{127}$. [1214] $f^{\circ} 74-74 v^{\circ}$

[221] XIII- De conseruacione status vinearum quas habemus apud Riuetam. [septembre $1225] f^{\circ} 74 v^{\circ}$ 
[222] XIIII- De blado quod percipimus in granchia de Foucheres. [1230] $f^{\circ} 74 v^{\circ}$

[223] XV- De vendicione quarumdem vinearum apud Irenciacum. [mars 1231] fo $74 v^{\circ}-75$

[224] XVI- De quibusdam rebus apud Irenciacum per commutacionem adquisitis. [juillet 1234] f 75

[225] XVII- De presentacione ecclesie de Disingiaco. [juillet 1224] fo75

[226] XVIII- De empcione quarumdem rerum apud Bleniacum. [avril 1238] f ${ }^{\circ} 75-75 v^{\circ}$

[227] XIX- De quitacione decem solidis quos abbas et conuentus Sancti Mariani habebant super furnum de Blagniacum. [juin 1239] $f^{\circ} 75 v^{\circ}$

[228] XX- De quitacione maiorie de Cussiaco. [août 1239] f $75 v^{\circ}$

[229] XXI- Item de empcione quarumdem rerum apud Blaaniacum. [juin 1239] $f^{\circ} 75 v^{\circ}$

[230] XXII- De empcione medietatis portus de riueta et quarumdem rerum sitarum apud Irenciacum ${ }^{128}$. [janvier 1239] $f^{\circ} 75 v^{\circ}-76$

[231] XXIII- De quitacione sex denariorum census super clausum de Riueta. [juillet 1243] $f^{\circ} 76$

[232] XXIIII- De empcione Heruinis de Solloines et Petri fratris eius. [1244] fo $76-76 \mathrm{v}^{\circ}$

[233] XXV- De quitacione duorum modiorum bladi quos magister Garinus de Chablies petebat in grangia de Bena. [juillet 1248] $f^{\circ} 76 v^{\circ}$

[234] XXVI- De vendicione sex sextariorum bladi nobis facta a Jacobo dicto Roncins. [29 novembre 1259] f $76 v^{\circ}-77$

[235] XXVII- De uno arpento vinee apud Iranciacum nobis a monialibus de cellis per commutacionem dato. [avril 1228] f 77

[236]- De presentatione ecclesie de Lineroliis ${ }^{129}$. [13 novembre 1257] f ${ }^{\circ} 77$ INCIPIUNT SCRIPTA DE BRECENIACO ET VAUCHARCI.

[237] I- Carta Hugonis comitis de Breceniaco et consuetudinibus ipsius ${ }^{130}$. [1104] fo79

[238] II- Item carta prefati comitis de saluamento eiusdem ville. [1114] f ${ }^{\circ} 79-79 v^{\circ}$

[239] III- Carta de Villa noua et de prepositis et iusticiis eiusdem uille. [1189] $f^{\circ} 79 v^{\circ}-80$

[240] IIII- De ecclesiis de Breceniaco et Vaucharci et de presentacione et institucione sacerdotis et de porcionibus utriusque partis ${ }^{131}$. [1179-1180] f ${ }^{\circ} 80-80 v^{\circ}$

[241] V- De eisdem ecclesiis eadem presentacione et institucione et de eisdem porcionibus inter nos et capellanum ${ }^{132}$. [1193] f $f^{\circ} 80 v^{\circ}-81$

[242] VI- De composicione facta inter nos et canonicos beati Stephani Trecensis super porcionibus utriusque partis in prefatis ecclesiis. [septembre 1195] f $f^{\circ} 81-81 v^{\circ}$

[243] VII- Item carta capituli Trecensis de predicta composicione. [[>septembre] 1195] $f^{\circ} 81 v^{\circ}$

[244] VIII- De iure patronatus ecclesiarum de Breceneio et Vaucharti et institucione sacerdotis. [juin 1219] $f^{\circ} 81 v^{\circ}$

[245] IX- Litera nona est de uerbo ad uerbum sicut VIII ${ }^{133}$. [juin 1219] $f^{\circ} 81 v^{\circ}$

[246] X- Item de ordinacione predictarum ecclesiarum. [1219] $f^{\circ} 81 v^{\circ}-82$

[247] XI- Item de ordinacione sustentacionis presbiteri de Brecenaio. [8 juin 1222] fo 82

[248] XII- Item de moderacione predicte odinationis facta. [8 juin 1222] fo $82-82 v^{\circ}$ 
[249] XIII- Item de ordinacione predictarum ecclesiarum de Brecenai et Vaucharti. [juin $1222] f^{\circ} 82 v^{\circ}$

[250] XIIII- De donacione cuiusdam domus apud Trecas. [1190] $f^{\circ} 82 v^{\circ}$

[251] XV- De medietate prouentuum ville de Coldra nobis a iudicibus delegatis per diffinitiuam sentenciam adiudicata. [février 1210] f ${ }^{\circ} 82 v^{\circ}-83$

[252] XVI- De plateis quas Mangerus tenuit apud Trecensum. [mai 1246] fos 83

[253] XVII- De possessione quarumdem decimarum prioratui de Brecenaio ab officii Senonensi adiudicata. [14 août 1249] fo $83-83 v^{\circ}$

[254]- Litera episcopi Trecensis super presentacione ecclesie de Vaucharcis. [26 avril $1286] f^{\circ} 83 v^{\circ}$

[255]- Carta de XXV libras solue anno quolibet super porcionem comitis sacre cesaris Pontis nascentis. [décembre 1269] $f^{\circ} 83 v^{\circ}$

DE SUMMA CASA.

[256] I- De potestate Pontis inter nos et comitem sacri Cesaris dimidiata ${ }^{134}$. [1176] fo $f^{\circ} 8$

[257] II- Confirmacio archiepiscopi Senonensis de prefata potestate Pontis Nascentis ${ }^{135}$. [vers 1176] $f^{\circ} 84-84 v^{\circ}$

[258] III- De elemosina Lisiardi apud Charnai. [1174] fo $84 v^{\circ}$

[259] IIII- De molendino de Sencasio ${ }^{136}$. [s.d.] fo $84 v^{\circ}$

[260] V- De seruicio cuiusdam mulieris et sobolis sue nobis concesso. [s.d.] fo $84 v^{\circ}-85$

[261] VI- De vendicione cuiusdam feodi apud Summam casam nobis facta ${ }^{137}$. [s.d.] fo 85

[262] VII- De terra Landrici de Draciaco apud Sanctum casium ${ }^{138}$. [s.d.] fo 85

[263] VIII- De centum solidos turonensium archiepiscopo senonensis soluendis pro procuracione apud sanctum casium. [juillet 1260] fo 85

[264] IX- De terris et possessionibus apud Summam Casam a duobus fratribus nobis quitatis. [19 mai 1261] fo $85-85 v^{\circ}$

[265] [Partage de la seigneurie de Ponessant entre le comte de Sancerre et l'abbaye de St-Germain] [septembre 1322] fo $85 v^{\circ}$

DE VILLARI.

[266] I- Carta Theobaldi comitis de diuersis consuetudinibus apud Villare Vinosum ${ }^{139}$. [18 août 1147$] f^{\circ} 86-86 v^{\circ}$

[267] II- De donacione Guillelmi vicecomiti sancti Florentini nobis apud Villare facta ${ }^{140}$. [1189] $f^{\circ} 86 v^{\circ}$

[268] III- De quodam furno apud Villare iuxta curiam monachorum ${ }^{141}$. [s.d.] f $86 v^{\circ}$

[269] IIII- Carta Raerii vicecomiti santi Florentini de censu xx solidos nobis ad eodem dato ${ }^{142}$. [s.d.] fo 87

[270] V- De censu x solidos pruuinensium apud Villare nobis dato. [1219] fo87

[271] VI- Vacat. $f^{\circ} 87$

[272] VII- De conuencionibus inter nos et Theobaldus comitem campanie super diuersis rebus $^{143}$. [septembre 1224] fo $87-87 v^{\circ}$

[273] VIII- Quod non tenemur adiuuare ad fortificiam comitis de Villa noua ${ }^{144}$. [16 janvier 1225] fo $87 v^{\circ}$ 

terminatis $^{145}$. [avril 1244] fo88-89 de Villari Vinoso pronunciato ${ }^{146}$. [juillet 1263] f f $^{\circ} 9-90 \mathrm{v}^{\circ}$

[277]- [Sans titre] [octobre 1235] fo $90 \mathrm{v}^{\circ}$

[278]- [Sans titre $]^{147}[1035] f^{\circ} 90 v^{\circ}-91$ DE SANCTO SALUATORE. $f^{\circ} 91 v^{\circ}-92$ [1161] fo $92-92 v^{\circ}$

[281] III- De quadam decima apud ecclesiam de Sanctis ${ }^{150}$. [s.d.] f f $^{\circ} 2 v^{\circ}$

[282] IIII- De collacione ecclesie de Sanctis ${ }^{151}$. [1125] fo $92 v^{\circ}$

[283] V- Vacat ${ }^{152} \cdot[1195] f^{\circ} 93$ Sancti Saluatoris. [1233] fo93 quarumdem terrarum. [mars 1242] fo $93 v^{\circ}$ 1259] fo $93 v^{\circ}-94$ avril 1265] fo94-94v

DE INFIRMARIA. auene et xx sexteriori vini ad infirmariam ${ }^{157}$. [21 novembre 1209] fo 95

[291] II- De eodem ${ }^{158}$. [1210] fo95 $f^{\circ} 95 v^{\circ}$ [18 octobre 1210] fo $95 v^{\circ}$ [août 1262] fo $95 v^{\circ}-96$

[297] VIII- De xx solidis in censu apud Escoliues. [1290] fo96 miles habuit nobis dato ${ }^{162}$. [juin 1239] $f^{\circ} 96-96 v^{\circ}$

[274] IX- De particione quorumdam hominum apud villarum. [décembre 1237] fo $87 v^{\circ}-88$

[275] X- Carta de diuersis articulis inter nos et dominum Milone de sancto Florentino

[276] XI- Litera officialis Autissiodorensis super quodam arbitrio inter nos et Guidonem

[279] I- De capella Sancti Johannis et de porcionibus monachorum et capellani ${ }^{148}$. [1157]

[280] II- De Digia, de iusticia in potestate Sancti Saluatoris, de Balliis et aliis rebus ${ }^{149}$.

[284] VI- Confirmacio quarumdem decimarum in ecclesia de Sanctis ${ }^{153}$. [1185] fo93

[285] VIII ${ }^{154}$ - Composicio facta cum priore sancti Amatoris de decima vini de clauso

[286] IX-Composicio facta inter abbatem et Philippum dictum Le Page super medietate

[287] X- De vendicione sepium et nemorum sancti Saluatoris ${ }^{155}$. [1207] f $f^{\circ} 93 v^{\circ}$

[288] XI- De usagio prioratus sancti saluatoris in nemore de Burceio ${ }^{156}$. [5 novembre

[289] XII- Diffinitiua sententia pro priore sancti Saluatoris contra Willemum Garneri. [3

[290] I- De donacione lxv solidis et unius hominis et heredum suorum et $\mathrm{xx}$ bichetum

[292] III- Item de eodem dono quo primum et secundum ${ }^{159}$. [1210] fo $95-95 v^{\circ}$

[293] IIII- Item de eodem dono quo primum, secundum et tercium ${ }^{160}$. [23 février 1258]

[294] V- De duobus numeris censualibus quitatis Lude de Lacon pro domo de pruuino.

4 [295] VI- Item de donacione domus de Pruuinum facta infirmarie nostre ${ }^{161}$. [1215] fo $95 v^{\circ}$

[296] VII- Item de centum solidis pruuinensis et censu xii denarios de domo de Pruuino.

[298] IX- De toto censu apud Autissiodorum que dominus Hugo de Autissiodorensis 
[299] X- Item alia litera officialis curie Autisiodorensis de predicto censu. [décembre 1251] $f^{\circ} 96 v^{\circ}$

[300] XI- Item de legato domine Mabilie uxore Iterii dicti Le Borne et concordat cum quatuor primis literis ${ }^{163}$. [1er février 1261] f $f^{\circ} 96 v^{\circ}-97$

[301] XII- De empcione prati apud Eriacum. [sam. 9 décembre 1251] fo97

[302] XIII- De quadam pecia prati subtus soerias infirmarie vendita. [samedi 5 août 1261] $f^{\circ} 97-97 v^{\circ}$

[303] XIIII- De annuo censu tercium denarios turonenses. [1262] $f^{\circ} 97 v^{\circ}$

DE OPERARIO.

[304]- De quadam decima nobis data in territorio quod dicitur Chenniau. [février 1237] $f^{\circ} 98$

[305]- De annuo redditu decem solidos. [juin 1239] f ${ }^{\circ} 98$

[306]- Sequens litera concordat cum prima. [août 1240] fo98v

[307]- Cartula de Molayo. [janvier 1263] fo $98 v^{\circ}$

[308]- Cartula de Molayo ${ }^{164}$. [janvier 1263] fo $98 v^{\circ}-100 v^{\circ}$

[309]- Cartula de unionis prioratus Meleredensis. [13 août 1413] fo $100 v^{\circ}-101 v^{\circ}$

[310]- Littera prepositure Ville noue regis de vendicione et remissione manus mortue facta hominibus nostris de Yranciaco. [27 novembre 1328] + Littera curie Autissiodorensis tabellionata de eadem materia de uerbo ad uerbum. for102-104

[311]- Littera obligatorum prepositure Ville Noue Regis de LX libris turonensis annuatim nobis debitis pro quittacione manus mortue de Yranciaco et pro tallia celerario. [27 novembre 1328] + Littera curie Autissiodorensis tabellionata de uerbo ad uerbum de eadem materia. $f^{\circ} 104 v^{\circ}-104 b i s$

1 [312]- Littera prepositure Ville noue regis de composicione decime de Yranciaco facta inter nos et Nicolas ac possessores vinearum dicti loci. [27 novembre 1328] + Littera curie Autissiodorensis tabellionata de eadem materia de uerbo ad uerbum. fo 104 bisv $^{\circ}-106$

332 [313]- Littera obligatoria prepositure Ville noue regis de quatuor solidis loco decime annuatim celerario nostro de Yranciaco super quolibet arpento debitis et impositis, et de quittacione usagiorum nemorum de super Yranciacum et de prouentaria. [27 novembre 1328] + Littera curie autissiodorensis tabellionata de eadem materia de uerbo ad uerbum. $f^{\circ} 106 v^{\circ}-107 v^{\circ}$

[314]- Littera sine carta curie Autissiodorensis tabellionata cum sigillum nostris abbatis et conuentus de permutacione tercie partis decime vinearum de Yranciaco ad XL libras annui redditus facta inter nos et curatum dicti loci confirmacione et decreto episcopi Autissiodorensis. [19 novembre 1328] f $107 v^{\circ}-108 v^{\circ}$

[315]- Littera obligatoria prepositure Ville Noue Regis de quinquaginta solidis ad Nicolis et possessoribus vinearum de Yranciaco nobis pro una uice debitis super quolibet arpento pro remissione manus mortue et propter quasdam franchisias eisdem concessas. [27 novembre 1328] + Littera curie Autissiodorensis tabellionata de eadem materia de uerbo ad uerbum. $f^{\circ} 108 v^{\circ}-109 v^{\circ}$

35 [316]- Littera obligatoria prepositure Ville Noue Regis de expensis instrumentorum et munimentorum et mensuracione arpentorum vinearum de Yranciaco factis occasione vendicionis manus mortue et composicionis decime ab incola dicte Ville refundendis et

Bulletin du centre d'études médiévales d'Auxerre | BUCEMA , Collection CBMA 
quilibet focus requisitus a nobis duos scillores ad nemora laudenda in prima tonsura tenebitur iustare quem in librarum. [27 novembre 1328] + Littera curie autissiodorensis tabellionata de eadem materia de uerbo ad uerbum. $f^{\circ} 109 v^{\circ}$

[317]- Littera prepositure Autissiodorensis de empcione rerum que fuerunt domini Henrici de Trisiaco militis. [25 juillet 1307] $f^{\circ} 110-110 v^{\circ}$

[318]- Littera solucionis quadraginta librarum turonensium dicto militi solutarum. [29 novembre1307] $f^{\circ} 110 v^{\circ}$

[319]- Littera curie Autissiodorensis quod donacio facta per vicarios domini Autissiodorensis episcopi in ecclesia de Bleigniaco non prouideret nobis. [6 juin 1329] fo111

[320]- Cest la charte de la iustice et poote de St Germain entre ces de St Germain et le conte. [janvier 1296] $f^{\circ} 115-117 v^{\circ}$

[321]- Cest la charte des declaracions danciens articles occurs contenuz en la premiere charte de saint Germani dauceurre et dou conte dauceurre et que lous ysages ne vaudra neus audit conte. [27 mars 1323] f $f^{\circ} 117 v^{\circ}-118$

[322]- Cest la charte que nous poons clore notre abbaye tout en tour de murs a creneaus et a tours et de lempeschement oste diceus qui yauoit este mis ala requeste dou conte. [27 mars 1323] f $f^{\circ} 118-118 v^{\circ}$

[323]- Charte dou conte daucerre de la mortassement de la terre de la Commoigne pour une certaine somme de deniers alui baillez pour cause de declarer les articles obscurs contenuz en la premiere charte. [27 mars 1323] f $f^{\circ} 118 v^{\circ}-119$

[324]- Littera qualiter dominus Autissiodorensis episcopus consentit que opus murorum nouorum consummetur.[25 janvier 1324] fo $119-119 v^{\circ}$

344 [325]- Littera bailliui Senonensis de amocione manus regie ad requisicionem comitis autissiodorensis. [24 juillet 1324] $f^{\circ} 119 v^{\circ}$

345 [326]- Littera bailliui Senonensis qualiter mendat gardiano nostro ut opus nostrum erga omnes deffendat. [25 mars 1324] fo $119 v^{\circ}$

346 [327]- Littera locum tenentis balliui Senonensis qualiter manus regia amota est ab opere nostro nouo. [17 mars 1324] fo 120

347 [328]- Lettre de Jehan conte dauceurre que de grace et non de debte il a este recehus a gesir en leglise monseigneur saint Germain dauceurre. [6 juin 1323] f $f^{\circ} 120$

348 [329]- De cestes mesmes lan vint et cinq. [1325] fo 120

349 [330]- Littera regis que contribuciones pro fortalicus tempore guerrarum factum non preiudicent nobis et priuillegiis nostris imposterum [15 mai 1317] $f^{\circ} 120-120 \mathrm{v}^{\circ}$

350 [331]- Litera regis que non compellamur ad fortalicia ciuitatis Autissiodorensis reperanda sed si fortalicium nostri castri sancti Germani tantum modo. [12 mai 1317] $f^{\circ} 120 v^{\circ}$

351 [332]- Comissio baillivis Senonensis de literis regis exequendis que non compellamur ad fortalicium ciuitatis autissiodorensis reparanda ut supra. [30 mai 1317] $f^{\circ} 120 v^{\circ}$

352 [333]- Littera officialis quod non compellamur ire ad processiones cathedralis ecclesie sollempnes nisi alias teneamur. [5 juin 1327] $f^{\circ} 120 v^{\circ}-121$

353 [334]- Contribucio priorum et ministrorum Sancti Germani pro reuelacione oneris debitorum abbacie ${ }^{165}$. [19 mai 1256] f $f^{\circ} 121-121 v^{\circ}$ 
[335]- Ordinacio facta de quibusdam pitanciis, tablenis tresoribus et quibusdam aliis. [9 novembre 1296] fo $121 v^{\circ}-122$

[336]- Litera officialis Autissiodorensis de pensione que habeamus super domum Iohannis ditti Coreit ${ }^{166}$. [s.d.] fo 122

[337]-Lettre de la Villeneuve que Iaquoz li Looraz cognuit estre hous saint Germain. [3 mars [13]28] fo 122

[338]- Instrumentum factum pro domino abbate super empcione tempore Johannis Ioe et eius uxoris. [23 novembre 1318] f f $^{\circ} 22-123$

[339]- Littera officialis tabellionata de permutacione cuiusdem pecie terre site versus insulam de Marconat ad triginta solidos anuui redditus super domini Johannes Coreti. [1318] $f^{\circ} 122-124 v^{\circ}$

[340]- Proclamaciones publice fatte pro vencidione domus defuncti Johannes Ludouici. [1326] $f^{\circ} 124 v^{\circ}$

[341]- Litere vendicionis domus defuncti Iohannis Ludouici virtute iudicatorum campanie. [3 mars 1326] fo $124 v^{\circ}$

[342]- Littera solucionis viginti libris turonensis facta in nundinis campanie pro domo defuncti Johannis Ludouici. [foire de Lagny 1326] f $124 v^{\circ}$

[343]- Confirmacio campanie de vendicione domus defuncti Iohannis Ludouici. [mars 1326] $f^{\circ} 124 v^{\circ}-126$

[344]- Littere Ysabellis dicte la Lornesse de excasura eius filie. [4 juillet 1317] $f^{\circ} 126 v^{\circ}-127 v^{\circ}$

[345]- Donacio omnium bonorum dicte la Lornesse nobis facta. [samedi 13 août 1317] $f^{\circ} 127 v^{\circ}-128$

[346]- Tradicio domus que Roma vocatur facta Ysabelli dicte La Lornesse ad vitam. [4 juillet 1317] $f^{\circ} 128-128 v^{\circ}$

[347]- Littere empcionis domorum ditti Lequarre. [22 avril 1300] fo $128 v^{\circ}-129$

[348]- Littera abbatis Clugniacensis que tenetur reddere nobis omnia priuilegia que habuit contra nos et faciunt iudicionem solum de monasterio nostro et omnibus aliis in quibus sit mencionem de monasterio nostro et aliis renunciat quantum ad nos ${ }^{167}$. [1er avril 1256] $f^{\circ} 129$

68 [349]- Littera domini Richardi cardinalis que condempnat cluniacensem ad idem ${ }^{168}$. [30 mars 1256] fo 129

[350]- Littera officialis Autissiodori de domo Zakarie de Mailhaco nobis quittata.

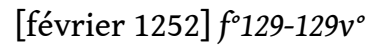

[351]- Littera officialis de eodem. [mars 1252] $f^{\circ} 129 v^{\circ}$

[352]- Littera Autissiodori officialis de eodem. [mars 1253] f 130

[353]- Littera officialis Autissiodori de vinea de Monte Falconis. [mercredi 1er décembre1288] fo130-130v ${ }^{\circ}$

[354]- Littera eiusdem de acquisicione domus et terre Robini Colasii de Perigniaco. [13 juin 1275] fo $130 v^{\circ}$

4 [355]- Littera de permutacione cuiusdam terre des Anglees. [22 février 1288] f $f^{\circ} 130 v^{\circ}-131$ 
[356]- Littera officialis curie decani Autissiodori de quadam emenda facta abbati Sancti Germani Autissiodorensi pro fractione cuiusdam domus iuxta portam sancti Symeonis. [août 1228] fo 131

[357]- Littera officialis Autissiodori de quittacione prepositure sancti Germani Autissiodori. [décembre 1276] fo131-131 $v^{\circ}$

[358]- Litera hostiensis episcopi que abbas sancti Germani usus fuit mitra et anulo in presencia pape. [s.d.] f $f^{\circ} 131 v^{\circ}$

[359]- Littera Henrici Autissiodori episcopi de presentacione ecclesie sancti Lupi Autissiodorensis. [11 octobre 1223] fo 132

[360]- Littera officialis Autissiodorensis de XVIII denariis curie census super quadam domo. [février 1224] fo132

[361]- Littera officialis Autissiodorensis de quadam emenda facta abbati sancti Germani pro verberacione cuiusdam hominis capituli ultra portam de Villa noua. [août 1228] $f^{\circ} 132$

[362]- Littera episcopi Eduensi de decem libras turonensis pro expensis factis in ecclesia sancti Germani peruottando. [1256] fo132

[363]- Littera de Escanno de Brueris. [janvier 1255] f ${ }^{\circ} 132-132 v^{\circ}$

[364]- Littera vendicionis rerum Boneti de Sancto Florentino. [dimanche 26 octobre 1320] $f^{\circ} 132 v^{\circ}-134$

[365]- Littera officialis tabellionata de eodem. [25 octobre 1320] fo 134

[366]- Littera episcopi Autissiodorensis que in capella de Perrigniaco possuit diuina officia perpetuo celebrari. [1321] fo134

[367]- Littera Autissiodorensis episcopi de eodem. [27 janvier 1324] f ${ }^{\circ} 134-134 v^{\circ}$

[368]- Littera prepositure Autissiodorensis que Robertus Li Bogues de Perrigniaco nobis tenetur in quindecim solidis annui redditus. [25 juillet 1309] fo $134 v^{\circ}-135$

[369]- Litera officialis Autissiodori de Saliceto quod fuit defuncti Iohannes de celario tabellionata. [15 novembre 1305] $f^{\circ} 135-135 v^{\circ}$

[370]- Littera curie nostre sigillata de eodem. [15 novembre 1305] $f^{\circ} 135 v^{\circ}$

[371]- Littera de franchisia Jaquini dicti Bute de Orgiaco. [15 janvier 1331] fo $136-136 v^{\circ}$

[372]- Littera Aramburgis relicte Stephani Seroe que quittat nobis quicquid iuris habet in prato de Breello de Perrigniaco. [3 septembre 1234] fo 137

[373]- Littera de sex arpentis vinearum apud Orgiacum quas emit Thomas Charsalee a capitulo beate Marie in ciuitate Autissiodorensi. [février 1266] fo 137-137v ${ }^{\circ}$

[374]- Littera de eisdem sex arpentis vinearum nobis a dicto Thoma donatis et concessis apud Orgiacum. [16 mars 1266] f $f^{\circ} 137 v^{\circ}$

[375]- Littera prepositure ville noue regis plantarum de Orgiaco a nobis cultoribus traditarum. [8 décembre 1327] $f^{\circ} 137 v^{\circ}-138$

[376]- Littera vel vidisse capituli nostri generalis plantarum de Orgiaco a nobis cultoribus traditarum. [5 août 1327] $f^{\circ} 138 v^{\circ}-139 v^{\circ}$

6 [377]- Littera ducis burgondie de empcione terre de Lacommoigne. [26 juillet 1325] $f^{\circ} 139 v^{\circ}-141$

[378]- Literra prepositure Autisiodorensis de eodem. [28 juillet 1325] fo141-142 
[379]- Littera comitis Autissiodorensis super admodiacione terre de la Commoigne. [27 avril 1323] fo $142-142 v^{\circ}$

[380]- Littera domini de Seilleniaco quomodo iusticia terre de La comoigne alta et bassa Petro de Saint Franchis noscitur pertinere. [31 mars 1317] f ${ }^{\circ} 142 v^{\circ}$

[381]- Littera composicionis fatte inter nos et dominum de Chanloto super decem bichetis ordei nobis ab ipso debitis super granchia de la Moree. [10 juillet 1324] $f^{\circ} 142 v^{\circ}-143 v^{\circ}$

[382]- Littera domini de Chanloto de decem bichetis ordei nobis ab ipso debitis super granchia de la Moree. [5 janvier 1324] $f^{\circ} 143 v^{\circ}-144$

[383]- Littera prepositure Autissiodorensis super terris, vineis, pratis et aliis possessionibus Johannis ditti Billebaut acceusatis apud Gurgiacum. [19 novembre 1314] $f^{\circ} 144-145 v^{\circ}$

[384]- Instrumentum publicum de eodem. [7 juin 1315] fo $145 v^{\circ}-146$

[385]- Littera prepositure Autissiodorensis de empcione rerum Johannis et Guillelmi de Migeto armigorum apud Gurgiacum. [22 avril 1332] fo 146-147

[386]- Littera de acquisitis apud Gurgiacum ab eisdem armigeris et de excasura Johanne sororis eorumdem. [22 avril 1332] fo 147-148

[387]- Littera empcionis prati de Nerone empti a Guillelmo piscatore de Appoigniaco et Melina eius uxore. [29 mai 1322] fo $148-148 v^{\circ}$

[388]- Renunciacio fatta a Petro dicto Bigon rebus armigerorum de Migeto apud Gurgiacum. [13 août 1332] fo $148 v^{\circ}$

HIC INCIPIUNT LITERE DE SUMMA CASA.

[389]- Primo littera vendicionis rerum de Summa Casa a Stephano ditto le Chemillat domino Dycour armigero et eius uxore nobis facta. [12 février 1328] $f^{\circ} 148 v^{\circ}-150 v^{\circ}$

[390]- Littera donationis Perrotino de Napples de rebus que sunt ante saeneaux quos tenet Regnaudus Liuoussis et rerum que fuerunt ala quartere [...] quos tenet Stephanus Remy. [9 mars 1328] fo $150 v^{\circ}-151$

[391]- Litera donacione nobis facte a Perrotini de Napples de feodo que tenebat ab ipso in parrochia de Summa Casa Stephanus Dircour armiger. [23 juillet 1328] f $f^{\circ} 151-151 v^{\circ}$

[392]- Copia litterarum rerum quas Perrotinus de Napples armiger emit a Girardo de Conferant dominus Derbloy et eius filio. [13 juillet 1328] fo $151 v^{\circ}-152$

2 [393]- Copia uel vidisse litere rerum quod Girardus de Corferant dominus de Arrablayo tenebat in feodum apud Summam Casam a Johanne de Tannerra. [s.d.] f $152-152 v^{\circ}$

3 [394]- Littera vendicionis nobis fatte a Iohanne de Tannerra de feodo rerum quas emimus apud Summam Casam. [10 janvier 1329] $f^{\circ} 152 v^{\circ}-153 v^{\circ}$

4 [395]- Littera comitis Barri quomodo confert monasterio nostro sancti Germani quicquid iure habebat in feodis in parrochia de Summa Casa. [26 septembre 1329] $f^{\circ} 154$

5 [396]- Littera comitis et comitisse de Ioigniaco de admortizacio rerum de Summa Casa. [22 juillet 1330] fo 154

6 [397]- Littera que ecclesia de Summa Casa nichil potest acquirere in terra nostra. [22 novembre 1262] $f^{\circ} 154-154 v^{\circ}$

[398]- Littera archiepiscopi Senonensis de decima noualium de Feins. [septembre 1269] $f^{\circ} 154 v^{\circ}$ 
[399]- Composicio facta super correctione monachorum inter nos et episcopum autissiodorensium. [3 avril 1304] f०155-157

[400]- Cest la leutre de la franchise Deauceurre ${ }^{169}$. [février 1255] fo $157-158 v^{\circ}$

[401]- Cest la leutre de la franchise de Perrigny ${ }^{170}$. [avril 1256] f $f^{\circ} 158 v^{\circ}-159$

[402]- Cest la leutre de la franchise de Villiers sur Tolon. [23 novembre 1340] fo159-160v ${ }^{\circ}$

[403]- Priuilegium Bonifacii octaui super procuracione sex dierum in iocundo aduentu episcopi autissiodorensis. [1303] $f^{\circ} 160 v^{\circ}-161 v^{\circ}$

[404]- Carta super remissione manus mortue et queste de Digia et de Forestis. [27 février 1343] fo $162-165$

[405]- Littera prepositure de Ville Noue Regis de eadem materia de uerbo ad uerbum. [27 février 1343] fo165-166

[406]- Littera sub sigillo prepositure Ville Noue Regis de eadem materia de uerbo ad uerbum. [s.d.] f $f^{\circ} 166$

[407]- Littera curie Autissiodorensis de compositione seu ordinatione decime vinearum de Digia ac de locis predictis. [29 février 1343] fo166-167

[408]- Littera de prepositure Ville Noue Regis de eadem forma sequitur de verbo ad verbum. [s.d.] fo $167-167 v^{\circ}$

[409]- [Amortissement d'Orgy et Chevannes]. [19 janvier 1367] ${ }^{171} f^{\circ} 167 v^{\circ}-168$

[410]- [Affranchissement de Jean dit Le Beat de St-Pris]. [9 novembre 1368] f $f^{\circ} 168 v^{\circ}-169$

[411]- [sans titre]. [15 juin 1384] fo 169

[412]- Donatio Urbani quinti pro reparatione ecclesia sancti Germani Autissiodorensis. [1366] fo $169 v^{\circ}$

2 [413]- [Donation d'un marc par Jean comte de Poitiers]. [7 avril 1364 ou 65] f $f^{\circ} 170-170 v^{\circ}$

[414]- Copie de la lettre concernant ceulx deuy ont leur pesche en la riuiere dudit lieu. [1397] fo $171-171 v^{\circ}$

34 [415]- [Sentences arbitrales de xxx des religieux de St-Germain contre Elix de Pontigny touchant la succession dun four dans la mainmorte de St-Germain]. [31 mai 1366] $f^{\circ} 171 v^{\circ}-172 v^{\circ}$

5 [416]- [Accord sur l'acquisition faite par les religieux de Pontigny dans la iustice de ceux de St-Germain ausquels ils accordent de faire lacquisition des paroisses valans dans les seigneuries de Perrigny]. [8 décembre 1395] fo $173-173 v^{\circ}$

[417]- Cest la franchise de Cussy les Courgi. [26 février 1456] fo $174-175 v^{\circ}$

[418]- [Ratification de la susdite transaction d'amortissement de Cussy]. [27 février 1356] $f^{\circ} 175 v^{\circ}-176$

[419]- Cest la procuracions de monseigneur Anthoine de Bueil conte de Sencerre par vertu de laquelle Jehan Bardin sire deçu son procureur a fait les foy et homaige et deuoir quil est tenu de faire ou chapitre de saint Germain daucerre au reuerend pere en dieu monseigneur labbe dudit lieu a cause de la terre de Pontnaissant lez chavin. [8 mai $1482] f^{\circ} 176 v^{\circ}$

9 [420]- [Hommage rendu a labbe et religieux pour la moitié de la seigneurie de Pontnaissant]. [17 octobre 1482] fo $177-179$ 

$f^{\circ} 179 v^{\circ}-186$

[423]- Affranchissement de Bleigny. [21 février 1478] f ${ }^{\circ} 191 v^{\circ}-194$ St-Germain pour le droit de patronnage]. [22 avril 1472] fo $194 v^{\circ}-196 v^{\circ}$ [21 avril 1472] + confirmation dudit traité. fo $196 v^{\circ}-197 v^{\circ}$ 1472] fo $197 v^{\circ}-201$

[427]- [ratification pat l'evêque d'Auxerre] [21 avril 1482] fo201 religieux de St-Germain]. [4 février 1399] f $f^{\circ} 201 v^{\circ}-202 v^{\circ}$

[430]- [Ratification dudit traité et accord]. [9 mars 1481] fo206-207 [27 décembre 1481] f $208-209 v^{\circ}$

[435]- [Découverte de corps dans une partie de l'abbaye]. [1667] fo214 l'abbaye de Molesmes]. [1639] fo214 Castra, diocèse de Bourges]. [1203] fo $214 v^{\circ}$ bois recouverte de peau blanche.

Composition

[421]- [Traité entre les religieux de St-Germain et chasteau de la ville daucerre par lequel les religieux quittèrent tous les droits qu'ils avaient... ]. [28 janvier 1469]

[422]- Affranchissement de la mainmorte de Héry. [20 mars 1459] f0186-191 ${ }^{\circ}$

[424]- [Transaction et accord entre les curés de St-Fargeau touchant lerection de la cure dudit St-Fargeau en collégiale soubz la residu de 50 sous de rente annuelle a labbaye de

[425]- [Transaction et accord passé par un chanoine de la collégiale St-Étienne de Gien entre le curé de St-Fargeau et le comte de Dammartin et ratifié par l'évêque d'Auxerre].

[426]- [Erection de la cure de St-Fargeau en collégiale a condition que l'office de doyen revienne audit cure lequel était de la presentation de l'abbé de St-Germain se nominerait alternativement par ledit abbe et comte de Dammartin fondateur]. [17 avril

[428]- [Amortissement de moitié de sa seigneurie de Gurgy achetee par l'abbé et les

[429]- [Traite et accord entre les chapitre de St-Germain et de St-Etienne d'auxerre touchant l'amortissement des heritages et mentions appartenant audit chapitre de StEtienne sur lesques les droits seigneuriaux, conditions profits et toutes conditions de recette et de dîme est audit chapitre de St-Germain]. [8 mars 1480] f $f^{\circ} 202 v^{\circ}-206$

[431]- [Autre ratification dudit traité et accord]. [20 mars 1481] fo207-208

[432]- [Accord et transaction entre les religieux de St-Germain et ceux de St-Marien].

[433]- Sentence contre les seigneurs de Lisle. [4 juillet 1425] f $209 v^{\circ}-212 v^{\circ}$

[434]- [Echange entre le comte de Joigny et l'abbaye de St-Germain]. [1209] fo214

[436]- [Don fait par un moine de portions du corps de saint Robert premier moine de

[437]- [Accord entre Raoul abbé de St-Germain et Eudes abbé de Sancti Germani de

Le cartulaire de la pitancerie ou petit cartulaire (Auxerre, B.M., ms. $162 \mathrm{G}$ )

Conservé à la bibliothèque municipale d'Auxerre sous la cote $162 \mathrm{G}$ (anc. 143), le cartulaire de la pitancerie de l'abbaye Saint-Germain, aussi appelé petit cartulaire par analogie avec son prédécesseur le grand cartulaire, est un codex composite de 145 feuillets de parchemin de grand format $(352 \mathrm{~mm}$ x $219 \mathrm{~mm})$. La reliure actuelle est en

Contrairement à son aîné, le cartulaire de la pitancerie ne comporte pas de préambule et donc pas de datation précise de l'entreprise. Le codex s'ouvre sur une table des actes foliotée séparément $\left(\mathrm{n}^{\circ} \mathrm{E}\right.$ à $\left.\mathrm{Hv}^{\circ}\right)$ et composée par les différents scribes. 
Une première phase, copiée par deux scribes principaux et plusieurs autres mains qui transcrivent de manière très ponctuelle quelques actes, occupe les folios I à LXXI verso. Elle comporte 260 actes numérotés en chiffres romains de 1 à 249 . La différence est liée au fait que certains actes ne sont pas numérotés et que d'autres portent le même nombre.

Une seconde phase, en écriture plus cursive probablement complétée au début du XIV ${ }^{\mathrm{e}}$ siècle, occupe les feuillets 72 à 137 verso. Elle comporte 67 actes numérotés en chiffres romains de 1 à 65 . Deux d'entre eux ne portent pas de numéro. Plusieurs mains ont œuvré à cette seconde phase de rédaction, dont l'une se dégage nettement.

Au-delà de cette organisation, le cartulaire n'a pas de schéma interne de composition. Les chartes y sont transcrites sans ordre chronologique même si parfois les cartularistes opèrent un regroupement des actes portant sur un même sujet.

La chronologie du manuscrit repose sur celles des actes.

Chronologie des actes

Le recueil comporte 327 pièces datées de 1185 à 1312. La répartition chronologique générale est moins éclatée que celle du grand cartulaire avec une grande majorité des actes du XIII ${ }^{e}$ siècle (305), auxquels il faut ajouter 1 acte du XII ${ }^{e}, 20$ du XIV siècle et 1 non daté.

\begin{tabular}{|cc|}
\hline Petit cartulaire de Saint-Germain d'Auxerre: & chronologie des actes \\
\hline XIle $^{e}$ & 1 \\
\hline XIIIe & 305 \\
\hline XIVe & 20 \\
\hline s.d. & 1 \\
\hline & Total $=327$ \\
\hline
\end{tabular}

L'acte le plus récent de le première phase composée par deux principales mains, avec quelques ajouts postérieurs, est de 1295, date qui fournit un terminus a quo pour ce petit cartulaire. La seconde campagne de rédaction suit d'une quinzaine d'années, sans doute peu après 1312. Plus des deux tiers des actes $(65,6 \%)$ qui y prennent place sont datés entre 1295 et 1312.

Cette datation fait du cartulaire de la pitancerie la $3^{\mathrm{e}}$ entreprise historiographique et archivistique des moines de Saint-Germain au XIII ${ }^{\mathrm{e}}$ siècle après le Grand cartulaire (1266) et les Gesta abbatum (1290).

Originaux conservés

466 Aucun.

Tradition

Encore moins étudié que son prédécesseur, la tradition du codex est très limitée. Le cartulaire de la pitancerie a fait l'objet de très peu d'éditions hormis quelques rares actes qui ont été publiés par l'abbé Lebeuf ou par M. Quantin dans son Cartulaire général de l'Yonne.

Manuscrits :

- Auxerre, B.M., ms.162 G (anc. 143), Stein nº 288.

- Auxerre, B.M., ms. 163 G (anc. 144). [Abrégé des cartulaires de Saint-Germain par dom G. Ternat en 1678, fo 73-93].

- Auxerre, B.M., coll. Bastard 294 (XXIV), fo 119-156. 


$$
\text { l'abbé Lebeuf et les autres par Maximilien Quantin dans son Cartulaire général de l'Yonne. }
$$
Table des actes du petit cartulaire de Saint-Germain d'Auxerre ${ }^{172}$ (Auxerre, B.M., ms. $162 \mathrm{~g}$ [anc. 143])

Éditions partielles :

-J. LEBEUf, Mémoires concernant l'histoire civile et ecclésiastique d'Auxerre et de son ancien diocèse, 4 vol., 1743, réed. Auxerre-Paris, 1848-1855.

- M. QUANTIN, Cartulaire général de l'Yonne, 2 vol., Auxerre, 1854-1860.

- M. QUANTIN, Recueil des pièces pour faire suite au cartulaire général de l'Yonne. XIII ${ }^{\mathrm{e}}$ siècle, Auxerre, 1873.

Part des actes publiés

[1] I- Quarta Petri, comitis Autissiodorensis ${ }^{173}$. [février 1216] $f^{\circ} 1$

[2] II- Quarta Matildis comitisse Niuernensis ${ }^{174}$. [17 juillet 1257] $f^{\circ} 1$

[3] III- Quarta domine Violete de Cerino. [1252] $f^{\circ} 1 v^{\circ}$

[4] IIII- Carta Symonis Boiche de Virziliaco. [1222] $f^{\circ} 1 v^{\circ}$

[5] V- Carta Symonis Boiche, Bertranni, Ranaldi, Theobaldi et Petri fratrum eius ${ }^{175}$. [novembre 1223] $f^{\circ} 1 v^{\circ}$

[6] VI- Carta Bernardi de Diuione burgensis de Villa Noua Regis. [1237] $f^{\circ} 1 v^{\circ}-2$

[7] VII- Carta H. de Autissiodoro militis dicti Bailledart. [juin 1239] fo 2

[8] VIII- Carta Milonis de Autissiodoro militis. [décembre 1251] fo 2

[9] IX-Carta H. archidiaconi Autissiodorensis. [août 1253] fo 2-2v

[10] X-Carta Galteri Brulechien et Luquete eius uxoris. [août 1251] $f^{\circ} 2 v^{\circ}$

[11] XI- Carta Herberti quondam decani Autissiodorensis. [1253] $f^{\circ} 2 v^{\circ}$

[12] XII- Carta magistri Iohannis de sancto Lupo. [février 1237] fo $2 v^{\circ}-3$

[13] XIII- Carta magistri I[ohannis] de sancto Lupo. [mars 1237] fo 3

[14] XIIII- Carta Guidoni de Orto armigeris. [février 1242] $f^{\circ} 3$

[15] XV-Carta nobilis mulier Elisabeth relicte Guido de Orto militis et Elisabeth [et Iohannes] filii eorumdem. [19 mars 1254] $]^{176} f^{\circ} 3-3 v^{\circ}$

[16] XVI- Carta Laurencii persone sancti Lupi Autissiodorensis. [juin 1239] $f^{\circ} 3 v^{\circ}$

[17] XVII- Carta Odonis F. defuncti Marduini sellarii et Agnete Otrandi sellarii. [novembre 1232] fo $3 v^{\circ}$

[18] XVIII- Carta de Britone et Marie uxor eius. [janvier 1247] fo $3 v^{\circ}-4$

[19] XIX-Carta Andree de Orgiaco. [1er mars 1249] $f^{\circ} 4$

[20] XX- Carta H. de sancta Paladia militis ${ }^{177}$. [1220] $f^{\circ} 4$

[21] XXI- Carta Cochini Autissiodorensis. [1223] $f^{\circ} 4-4 v^{\circ}$

[22] XXII- Carta Garnerii dicti Cornate ciuis Autissiodorensis. [août 1290] fo $4 v^{\circ}$

[23] XXIII- Carta Felicis de Sartrino. [avril 1280] $f^{\circ} 4 v^{\circ}$

[24] XXIIII-Carta Herberti de Cheuannis militis et Iohannis fratris eius. [avril 1226] $f^{\circ} 4 v^{\circ}$

[25] XXV-Carta Garnerii dicti Masquerelli. [janvier 1225] fo $4 v^{\circ}$

[26] XXVI- Carta Lore relicte Lebini canbitoris ${ }^{178}$. [1219] $f^{\circ} 4 v^{\circ}-5$ 
[27] XXVII- Carta Girardi Pobele et Adeline eius uxoris. [janvier 1222] f 5

[28] XXVIII- Carta Narduini Sellarii. [1215] f 5

[29] XXIX-Carta Odonis Mardini. [juillet 1237] f ${ }^{\circ} 5$

[30] XXX-Carta Guillermi generis Asardi de Ponte et Marie eius uxoris. [1256] $f^{\circ} 5$

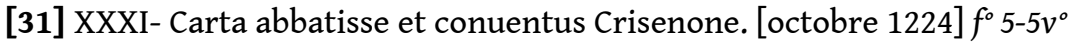

[32] XXXII- Carta Iterii filii defuncti Burgondi et Marie eius uxoris. [février 1232] $f^{\circ} 5 v^{\circ}$

[33] XXXIII- Carta Theobaldi Marpandi et Emengardis uxoris eius. [17 janvier 1256] $f^{\circ}$ $5 v^{\circ}$

[34] XXXIIII- Carta Anselli de Porta fiscali. [mars 1229] $f^{\circ} 5 v^{\circ}-6$

[35] XXXV-Carta Aramburgis Lamosse et Guillelmi filii eius. [6 décembre1223] fo 6

[36] XXXVI- Carta Bernardi mariti Emengardis Lacocerelle. [13 février 1252] $f^{\circ} 6$

[37] XXXVII- Carta Regnaudi Clarui. [mai 1224] $f^{\circ} 6$

[38] XXXVIII- Carta H[ugonis] de Subtus Ulmo armigeri. [août 1238] fo 6

[39] XXXIX-Carta Guillelmi de Fontenello militis. [juin 1226] $f^{\circ} 6-6 v^{\circ}$

[40] XL-Carta nobilis mulieris Lucie de Boiaco. [juin 1227] $f^{\circ} 6 v^{\circ}$

[41] XLI- Carta Iohannis dicti militis et Marie eius uxoris. [1259] $f^{\circ} 6 v^{\circ}$

[42] XLII- Carta Milonis Limananz. [mars 1250] $f^{\circ} 6 \mathrm{v}^{\circ}$

[43] XLIII- Carta Guillelmi et Granerii fratres liberi defuncti Galteri dou biez. [décembre 1253] $f^{\circ} 7$

[44] XLIIII- Carta P[etri] de Forti terra. [août 1225] $f^{\circ} 7$

[45] XLV- Carta Stephani et eius uxoris. [juin 1237] $f^{\circ} 7$

[46] XLVI- Carta Acherii prioris Saissiaci. [janvier 1224] $f^{\circ} 7$

[47] XLVII- Carta Humberti Maquerelli et eius uxoris. [mars 1246] $f^{\circ} 7$

[48] XLVIII- Carta Roberti dicti Canis. [septembre 1229] fo 7-7 ${ }^{\circ}$

[49] XLIX- Carta Radulphi la Plaignie et Stephani Pichet. [avril 1222] $f^{\circ} 7 v^{\circ}$

[50] L- Carta Eschardi et Ysabelli eius uxoris. [mars 1259] $f^{\circ} 7 v^{\circ}$

[51] LI- Carta Arnulphi Marpaut. [mars 1239] $f^{\circ} 7 v^{\circ}-8$

[52] LII- Carta I[ohannis] filii Morelli Marpaut. [6 mai 1250] $f^{\circ} 8$

[53] LIII- Carta Stephanus Bestornez et Christiana eius uxoris. [février 1253] fo 8

[54] LIIII- Carta Milonis Carpentarii et eius uxoris. [août 1244] $f^{\circ} 8-8 v^{\circ}$

[55] LV- Carta Stephani de Poseya presbiteri. [décembre 1234] $f^{\circ} 8 v^{\circ}$

[56] LVI- Carta Ameline relicte H[ugonis] carnificis. [15 février 1247] fo $8 v^{\circ}$

[57] LVII- Carta Guillemi Mircerii de Villa Noua Regis. [octobre 1239] $f^{\circ} 8 v^{\circ}$

[58] LVIII- Carta Stephani Marchiam Germani domini filii eiusdem Stephani et uxoris dicti Germani. [1225] f ${ }^{\circ} 8 v^{\circ}-9$

[59] LIX- Carta H[ugonis] Tuechien. [avril 1257] fo 9

[60] LX- Carta Regnaudi dicti Chenal et Hersandis eius uxoris. [juillet 1251] fo 9

[61] LXI- Carta Regnaudi dicti Chenal et Hersandis eius uxoris. [août 1259] fo 9-9v ${ }^{\circ}$

[62] LXII- Carta Leodegarii dicti Compani. [février 1250] fo $9 v^{\circ}$ 
[63] LXIII- Carta P[etri] de Sordolio fratris Stephani granetarii. [février 1253] f $f^{\circ} 9 v^{\circ}$

[64] LXIIII- Carta magistri P[etri] de Puseya clerici. [9 avril 1250] $f^{\circ} 9 v^{\circ}-10$

[65] LXV- Carta Adam boni et Clare eius uxoris. [6 février 1253] fo 10

[66] LXVI- Carta Humberti Ioart. [novembre 1224] fo 10

[67] LXVII- Carta Io[hannis] Ferrici prepositi autissiodorensis. [avril 1248] f $f^{\circ} 10-10 v^{\circ}$

[68] LXVIII- Carta Droini mercator et Adeline eius uxoris. [7 août 1254] f $f^{\circ} 10 v^{\circ}$

[69] LXIX-Carta P[etri] maioris de Eriaco et Marie eius uxoris. [1244] fo $10 v^{\circ}$

[70] LXX- Carta Roberti de Arciis presbiteri beate Martini autissiodorensis et Stephani fratris eius. [mai 1260] $f^{\circ} 10 v^{\circ}$

[71] LXXI- Carta Matildis comitisse Niuernensis. [5 octobre 1243] fo $10 v^{\circ}-11$

[72] LXXII- Carta Io[hannis] de Brena militis. [juin 1239] fo 11

[73] LXXIII- Carta Io[hannis] Charez et Eremburgis eius uxoris.[mars 1242] fo 11

[74] LXXIIII- Carta Bartholomei nepotis R. quondam cantoris Autissiodorensis. [3 octobre 1247] fo 11

[75] LXXV- Carta Andree monetarie et eius uxoris. [jan. 1236] fo 11-11v ${ }^{\circ}$

[76] LXXV1 ${ }^{179}$ - Carta Guerini de Roureto et Ysabellis eius uxoris et Iohannis Morelli eiusdem loci. [juillet 1269] fo $11 v^{\circ}-12$

[77] LXXVII- Carta Guillelmi filii quondam defuncti Guillelmi quondam prepositi de Roureto, et Margarita materis dicti Guillelmi. [avril 1269] fo 12

[78] LXXVIII- Carta Iohannis dicti Guignorriz. [août 1260] fo 12-12v

[79] LXXIX- Carta Willelmi de Fontenelli militis. [juin 1226] $f^{\circ} 12 v^{\circ}$

[80] LXXIX ${ }^{180}$ - Carta Engenulphi canonici sancte Marie de Braio qui dedit nobis $\mathrm{xxx}$ solidos super vineam suam de Pucello sitam apud Betriacum cellerarius de Yranciaco debet. [1202] $f^{\circ} 12 v^{\circ}$

[81] LXXX- Carta domini Io[hannis] Berardi militis. [1212] fo 13

[82] LXXXI- Carta Guillelmi de Etrisiaco militis filii defuncti Agnetis Labrarde. [décembre 1229] fo 13

[83] LXXXII- Carta P[etri] Catonis et Marie eius uxoris. [février 1256] f ${ }^{\circ} 13$

[84] LXXXIII- Carta G[uillelmi] de Puteo et Gilete eius uxoris. [novembre 1246] f ${ }^{\circ} 13-13 v^{\circ}$

[85] LXXXIIII- Carta P[etri] de molendino Cotini et Eremburgis eius uxoris. [mar. 29 août 1256] fo $13 v^{\circ}$

[86] LXXXV- Carta Stephani de Forestis et Marie eius uxoris. [août 1256] fo $13 v^{\circ}$

[87] LXXXVI- Carta Bernardi de Forestis et Marie eius uxoris. [février 1256] fo $13 v^{\circ}-14$

[88] LXXXVII- Carta Bernardi de Forestis et Marie eius uxoris. [février 1256] fo 14

[89] LXXXVIII- Carta Iocelini de Digia militis. [10 septembre 1244] fo 14

[90] LXXXIX- Carta Germani forestarii de Digia. [décembre 1246] fo 14

[91] LXXXX-Carta Andree de Villa Noua Regis Nauarrie. [1239] fo 14

[92] LXXXXI- Carta D. uxor Hugonis militis de Chevannis ipsius H. et filiis suis H., Her. et Jo. ${ }^{181}$ [avril 1208] $f^{\circ} 14 v^{\circ}$

[93] LXXXXII- Carta Emengardis humilis abbatissa de Crisenone. [juillet 1227] $f^{\circ} 14 v^{\circ}$ 

s[ancti] G[ermani]. [avril 1233] f $f^{\circ} 14 v^{\circ}-15$

[98] LXXXXVII- Carta Odonis maioris de Escanno. [août 1246] fo 15 15 $f^{\circ} 15-15 v^{\circ}$ novembre 1295] $f^{\circ} 15 v^{\circ}-16$ dictas pecias. [1312] fo 16 1251] $f^{\circ} 16 v^{\circ}-17$

[108] CV- Carta Siluestri de Legniaco. [mars 1233] fo 17 $f^{\circ} 17-17 v^{\circ}$

[112] CIX-Carta Siluestri de Legniaco. [janvier 1235] fo $17 v^{\circ}-18$

[113] $\mathrm{CX}^{183}$ - Carta P[etri] curati de Yranciaco. [décembre 1254] fo $18 v^{\circ}$

[114] CXI- Carta P[etri] presbiteri de Yranciaco. [juillet 1258] $f^{\circ} 18 v^{\circ}$

[115] CXII- Carta Droyni dicti La Cale. [15 octobre 1257] f $18 v^{\circ}-19$

[116] CXIII- Carta Regnaudi Aubigois. [juillet 1234] fo19

[117] CXIIII- Carta Guillelmi Labeton de Yranciaco. [avril 1242] fo 19

[118] CXV- Carta Guidonis domini de Mallianiaci. [octobre 1224] fo 19

[119] CXVI- Carta Amaurici de Heriaco. [1211] f $f^{\circ} 19-19 v^{\circ}$ $f^{\circ} 19 v^{\circ}$ solidis que habemus super census de Bena. [18 décembre 1275] f $19 v^{\circ}$

[95] LXXXXIIII- Carta Stephani Canbellani et servientis domini $\mathrm{R}$ [egnaudi] abbatis

[96] LXXXXV-Carta Stephani Gratepeaul de s[ancto] Geruasio. [novembre 1230] $f^{\circ} 15$

[97] LXXXXVI- Carta Symonis Morelli de Digia et Agnetis eius uxoris. [1242] $f^{\circ} 15$

[99] LXXXXVIII- Carta Regnaudi dicti Regis de Digia et Marie eius uxoris. [jan. 1245] $f^{\circ}$

[100] LXXXXIX- Carta Gi[rardi], Humbaudi, Hurriaci et Herberti de Taneriis. [août 1225]

[101] LXXXXIX ${ }^{182}$ - Carta de quadam pecia terre que nostra est sita apud Seilleniacum quam tenet Symonetus Forestarii et eius uxor et debent eam edificare in vineam. [22

[102] LXXXXIX- Carta Ysabellis uxoris Guidonis de Roureto que quitauit nobis quadam peciam terre sitam in territorio de Hurtebise pro deffectu census nostri debiti super

[103] C- Carta Symonis de Gurgiaco et Adeline eius uxoris. [14 janvier 1237] $f^{\circ} 16 v^{\circ}$

[104] CI- Carta Laurencii Carpentarii et eius uxoris Aueline. [mars 1236] $f^{\circ} 16 v^{\circ}$

[105] CII- Carta Siluestri de Legnorelis et Ameline eius uxoris. [1235] $f^{\circ} 16 v^{\circ}$

[106] CIII- Carta Compani de Heriaco presbiteri. [décembre 1253] fo $16 v^{\circ}$

[107] CIIII- Carta P[etri] Morelli filii Ulrici de Villa Maris et eius uxoris. [septembre

[109] CVI- Carta Stephani Forestarii de Monte et Ysabellis eius uxoris. [septembre 1251]

[110] CVII- Carta Villani de Soumesot militis et Alienor eius uxoris. [mai 1227] $f^{\circ} 17 v^{\circ}$

[111] CVIII- Carta Guillelmi Boussart de Lignerellis. [juillet 1233] $f^{\circ} 17 v^{\circ}$

[120] CXVII- Carta domini Guidonis de Bena militis et M[arie] eius uxoris ${ }^{184}$. [avril 1240]

91 [121] CXVII ${ }^{185}$ - Summa data contra dominum Ansellinum de Triangulo militem de $\mathrm{xx}$ 
[122] CXVII ${ }^{186}$ - Carta Iohannis dicti Porreni qui recognouit se debere V solidos super vineam suam de collibus de Augiaco. [9 janvier 1295] $f^{\circ} 19 v^{\circ}-20$

[123] CXVIII- Carta nobilis mulieris dicte dominam de Perregniaco. [mars 1225] fo 20

[124] CXIX- Carta Guillemi domini Montis sancti Iohannis. [décembre 1235] fo20

[125] CXX-Carta Willelmi domini Montis sancti Iohannis. [juillet 1224] fo20

[126] CXXI- Carta Henrici presbiteri ecclesie de sancto Ferreolo. [21 décembre 1240] $f^{\circ} 20 v^{\circ}$

[127] CXXII- Carta Seguini de Meniers militis. [1231] fo $20 v^{\circ}$

[128] sans titre ${ }^{187}$. [1239] $f^{\circ} 20 v^{\circ}$

[129] sans titre ${ }^{188}$. [février 1239] fo $20 v^{\circ}$

[130] CXXIII- Carta Juliane preposite de Willane et liberorum eius. [novembre 1229] $f^{\circ} 20 v^{\circ}$

[131] CXXIIII- Carta Leobaudi Ieremie militis. [mars 1220] fo $20 v^{\circ}-21$

[132] CXXV-Carta Copini de Gurgiaco piscatoris. [février 1268] fo21

[133] CXXVI- Carta Narduini de Orgiaco et Aelisdis eius uxoris. [août 1268] fo21-21v ${ }^{\circ}$

[134] CXXVII- Carta Lanberti de sancto Petro clerici. [19 janvier 1268] f $f^{\circ} 21 v^{\circ}$

[135] CXXVIII- Carta Narduini de Orgiaco et Aelidis eius uxoris. [mars 1267] f $f^{\circ} 21 v^{\circ}-22$

[136] CXXIX ${ }^{189}$ - Carta Martini Fulcherii et Elisabeth eius uxoris. [mar. 26 mars 1269] $f^{\circ} 22-22 v^{\circ}$

[137] CXXX- Carta Martini Fulcherii et Ysabella eius uxoris. [mar. 26 mars 1269] $f^{\circ} 22 v^{\circ}-23$

[138] CXXXI- Carta Martini Fulcherii et eius uxoris. [juillet 1258] f $f^{\circ} 23-23 v^{\circ}$

[139] CXXXII ${ }^{190}$ - Carta domini Iohannis abbatis sancti Germani qui dedit nobis et domino Laurencio curato de Summa Casa licenciam tenendi vii arpenta terre arabilis cum i arpentum prati amortizata qua dedit nobis predictus Laurencius. [mars 1270] $f^{\circ}$ $23 v^{\circ}$

[140] CXXXII ${ }^{191}$ - Carta Henrici Cheurardi de veteribus campis. [2 janvier 1272] fo24-24v

[141] CXXXIII- Carta Aligreti de sancto Prisco clerici et Lore eius uxor. [juillet 1259] $f^{\circ} 24 v^{\circ}$

2 [142] CXXXIIII- Carta Agnetis de sancto Verano facta super rebus de Escoliuis. [octobre 1284] $f^{\circ} 24 v^{\circ}-25$

[143] CXXXV-Carta empcionis domus de Iamoy facte a Regnaudo de Iamoy et uxore. [9 mai 1262] fo 25

[144] CXXXVI- Carta arbiteri prelati a Michaele archidiaconi contra dominam de Mala vicina et eius liberos heredes defuncti Galcheri. [1281] fo $25-25 v^{\circ}$

[145] CXXXVII- Carta compromissi facti in Michaelem archidiaoni a domina de Mala Vicina. [septembre 1280] $f^{\circ} 25 v^{\circ}-26$

6 [146] CXXXVIII- Carta executorum defuncti Galcheri militis de viginti solidis assessis super terram dicti defuncti. [octobre 1277] fo 26

17 [147] CXXXIX- Carta Guillelmi Aillot emptionis terre sue de Villari Vinoso. [1264] $f^{\circ} 26-26 v^{\circ}$ 

[9 juin 1271] f $26 v^{\circ}$

[149] CXLI- Carta de eodem molendino. [1270] fo $26 v^{\circ}-27$ $1272] f^{\circ} 27-27 v^{\circ}$ $f^{\circ} 27 v^{\circ}$ $f^{\circ} 27 v^{\circ}-28$ domine de Villa Ferreoli. [20 juin 1277] fo28 1260] $f^{\circ} 28$ $f^{\circ} 28 v^{\circ}$ medio. [18 mai 1261] fo29 1262] f $f^{\circ} 29$ $f^{\circ} 29-29 v^{\circ}$ Colini Belini. [16 mai 1282] fo $29 v^{\circ}-30$

[162] CLIIII- Carta Stephani succentoris. [25 juin 1283] f $f^{\circ} 30$ Montein. [novembre 1277] f $f^{\circ} 30-30 v^{\circ}$ [23 juin 1277] fo $30 v^{\circ}$ ascensu fori. [13 avril 1269] $f^{\circ} 30 v^{\circ}-31$ unum quarterium vinee. [17 avril 1269] $f^{\circ} 31 v^{\circ}$

[168] CLX- Carta Johannis Morelli. [1284] fo32-33 Montem. [juillet 1271] fo33-33v ${ }^{\circ}$

[170] CLXII- Carta Richerii Blondelli. [aout 1271] fo $33 v^{\circ}$ $f^{\circ} 33 v^{\circ}-34$

[148] CXL- Carta Hugonis Pullam presbiteri de dono octaue partis cuiusdem molendini.

[150] CXLII- Carta Droyni Griffon et Ysabellis eius uxoris de viginti solidis. [30 août

[151] CXLIII- Carta Jaquini canis de dono viginti solidorum. [août 1275] fo27v ${ }^{\circ}$

[152] CXLIIII- Carta emptionis census empti ab abbatissa de Crisenone. [juillet 1227]

[153] CXLV- Carta de viginti solidis super census domine de villa Ferreoli. [20 juin 1277]

[154] CXLVI- Carta de viginti duobus solidis censualis percipiendis super nemora

[155] CXLVII- Carta sexaginta solidis super prepositatum de sancto Prisco ${ }^{192}$. [avril

[156] CXLVIII- Carta emptionis grangie de Reuillon. [22 décembre 1257] fo $28 v^{\circ}-29$

[157] CXLIX- Carta Gaufridi dicti senex armigeri et Marie eius uxoris. [novembre 1260]

[158] CL- Carta Hugonis de Chassein armigeri de dono terrarum suarum de Monte

[159] CLI- Carta vendicione terre Guillelmi Mathei armigeri de Monte medio. [juin

[160] CLII- Carta magistri Stephani de Vannosia pro vinea de Corcellis. [24 mai 1274]

[161] CLIII- Carta Stephani de Doeto succentoris Autissiodorensis de empcione platee

[163] CLV- Carta emptionis census priorisse et conuentus sancti Dominici iuxta

[164] CLVI- Carta Humbaudi de Corgiaco militis et eius uxoris de tribus sextariis auene.

[165] CLVII- Carta de decem solidis pro uxore Herberti Brichemer sitis super domum in

[166] CLVIII- Carta Iohannis Salomonis et Odearis eius uxoris. [23 mai 1273] fo31-31v ${ }^{\circ}$

[167] CLIX-Carta Hueti filii defuncti Obelini minagerii de quinque solidis assessis super

[169] CLXI- Carta rerum emptarum a Recherio Blondelli de Petro de Monte apud

[171] CLXIII- Carta Laurencii curati de Summa Casa presbiteri. [7 novembre 1271] 
[172] CLXIIII- Carta sextius bladi empti a Regnaudi Chartrene. [7 décembre 1269] $f^{\circ} 34-34 v^{\circ}$

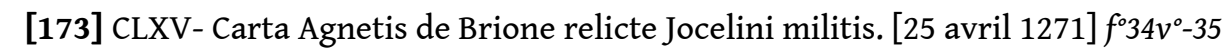

[174] CLXVI- Carta relicte Iacobi Ruffi de Briennone pro rebus qui dedit nobis apud Montem. [20 novembre 1274] fo $35-35 v^{\circ}$

[175] CLXVII- Carta Johannis dicti de Uconon filii quondam defuncti Iohannis Beide. [mai 1271] $f^{\circ} 35 v^{\circ}-36$

[176] CLXVIII- Carta Johannis de Uconon armigeri. [22 juillet 1275] fo $36-36 v^{\circ}$

[177] CLXIX- Carta Lamberti de sancto Petro clerici. [20 janvier 1268] fo $36 v^{\circ}$

[178] CLXX-Carta domine Ysabellis relicte quondam Petri de Chamloto militis. [2 mai $1274] f^{\circ} 36 v^{\circ}-37$

[179] CLXXI- Carta Girardi de Monte clerici et Ysabellis eius uxoris. [mars 1269] fo $37-37 v^{\circ}$

[180] CLXXII- Carta comani de Heriaco presbiteri. [décembre 1253] f ${ }^{\circ} 37 v^{\circ}$

[181] CLXXIII- Carta prati empti a Jaqueto filio Robini de Heriaco. [mars 1205] fo $37 v^{\circ}-38$

[182] CLXXIIII- Carta Guidonis Saquerelli et Osanne eius uxoris. [1257] fo38

[183] CLXXV- Carta rerum emptarum ab Adelina relicta Alberici alemanni et Ysabellis eius filia. [mars 1273] fo $38-38 v^{\circ}$

[184] CLXXVI- Carta Aalisis dicte la Guignorrie et eius executorum de dono vineo de Lamere. [mars 1273] fo $38 v^{\circ}-39$

[185] CLXXVII- Carta alia de la Guignorrie. [28 octobre 1272] fo39-39v ${ }^{\circ}$

[186] CLXXVIII- Carta de rebus emptis a relicta maioris de Roureto. [31 mai 1272] fo39v ${ }^{\circ}$

[187] CLXXIX- Carta terciarum emptarum ab Iterio de Venussia milite. [22 avril 1256] $f^{\circ} 39 v^{\circ}$

[188] CLXXX-Carta magistro Herueo Borno. [26 mars 1288] fo 40

[189] CLXXXI- Carta magistri Nicholai pedagii clerici. [24 février 1288] f $f^{\circ} 40$

[190] CLXXXII- Carta Robeleti Latomi. [août 1289] fo $40-40 v^{\circ}$

[191] CLXXXIII- Carta de domo de Escanno qua magister Humbertus curatus dicti loci dedit nobis. [1289] $f^{\circ} 40 v^{\circ}$

[192] CLXXXIIII- Carta Guillelmi Faissier. [12 mai 1289] f $40 v^{\circ}-41 v^{\circ}$

[193] CLXXXV ${ }^{193} f^{\circ} 41 v^{\circ}-42$

[194] CLXXXVI- Item alia carta Stephani de Dymone. [3 février1264] fo42-42v ${ }^{\circ}$

[195] CLXXXVII- Carta Tornodorensis. [jan. 1271] f $f^{\circ} 42 v^{\circ}-43$

[196] CLXXXVIII- Sententia diffinitiua lata contra Hurtadum de Vaginis super quamdam terram. [1290] fo $43-43 v^{\circ}$

[197] CLXXXIX- Carta de quinque solidis apud Luciacum. [1268] fo $43 v^{\circ}-44$

[198] CLXXXX- Carta Agnetis relicte Stephani de Roseriis. [1276] fo 44

[199] CLXXXXI- Carta de decem solidis quos habemus per Heymone quondam curato de Bleigniaco. [1286] $f^{\circ} 44 v^{\circ}-45$

[200] CLXXXXII- Carta Guillelmi de Orgiaco dicti Robeau. [21 septembre 1286] fo 45 
[201] CLXXXXIII- Carta domine Dyonisie Senonensis quod dedit nobis quinque solidorum super domum suam de Fonte. [29 août 1272] fo $45-45 v^{\circ}$

[202] CLXXXXIIII- Carta Guillelmi dicti Blanchet. [27 novembre 1275] f $45 v^{\circ}$

[203] CLXXXXV- Carta contra Guillelmum et Hugonem de Marciaco in Bazeio super duobus quartellis bladi. [10 décembre 1273] fo $45 v^{\circ}$

[204] CLXXXXVI- Carta Symonis de Tornodoro presbiter. [mars 1286] fo $45 v^{\circ}-46$

[205] CLXXXXVII- Carta Johannis de sancto Florentino qui recognouit quo mater sua legauerat nobis uiginti solidos super grangiam suam sitam iuxta portum Uille noue. [15 janvier 1250] f $f^{\circ} 6$

[206] CLXXXXVIII- Carta Stephani de Puluereno. [juin 1272] fo46-46v

[207] CLXXXXIX-Carta Amaurici Cordueunarii de vinea de Lange. [1203] $f^{\circ} 46 v^{\circ}$

[208] CC- Carta Michael dicti Tribolauz carpentarii. [31 août 1285] $f^{\circ} 46 v^{\circ}-47$

[209] CCI- Carta de empcione domus relicte Gaufridi Segaut retro monasterium nostrum site. [22 mai 1287] f $f^{\circ} 4-47 v^{\circ}$

[210] CCII- Carta Bartholomei dicti Grimillauz. [26 octobre 1281] f $47 v^{\circ}$

[211] CCIII- La chartre Michiauz Tribolauz. [31 août 1285] f $f^{\circ} 4 v^{\circ}-48 v^{\circ}$

[212] CCIIII- Carta de domo Petri Morini et uxore eius. [4 août 1284] fo $48 v^{\circ}-49$

[213] CCV- Carta Johannis Papelardi et Johannis Mathei de sex solidis. [27 mai 1271] $f^{\circ} 49-49 v^{\circ}$

[214] CCVI- Carta Adeline de Tornaio de decem solidis. [9 mars 1274] fo $49 v^{\circ}$

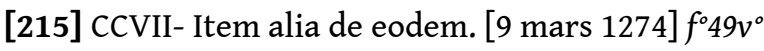

[216] CCVIII- Carta de tenetura dicti Maucinion. [4 juillet 1253] fo $49 v^{\circ}-50$

[217] CCVIII $^{194}$ - Carta de pratis que fuerunt quondam Herberti decani Autissiodorensis. [octobre 1242] fo50

[218] CCIX- Carta Laurencii presbiteri de Summa Casa. [mars 1270] fo50-50v ${ }^{\circ}$

[219] CCX-Carta de quodam vinea in capeta. [3 décembre 1261] fo50v ${ }^{\circ}$

[220] CCXII ${ }^{195}-C a r t a ~ B e r a u d i ~ c l e r i c i ~ d e ~ q u a n d a m ~ d o m o . ~[m a i ~ 1264] ~ f o 50 v^{\circ}-51$

[221] CCXIII- Carta Stephani quondam prepositi sancti Germani de quindecim solidis. [décembre 1248] fo51-51v

[222] CCXIIII- Item carta Stephani prepositi sancti Germani de eodem. [24 avril 1271] $f^{\circ} 51 v^{\circ}$

[223] CCXV- Carta de terris de Orgiaco que fuerunt magistri Thome Charsalee. [juin 1265] fo $51 v^{\circ}-52$

[224] CCXVI- Carta de decem solidis pro Petro Guignorri. [21 mars 1272] fo52-52v ${ }^{\circ}$

[225] CCXVII- Item carta de triginta solidis pro eodem. [14 octobre 1273] fo52 $v^{\circ}-53$

[226] CCXVIII- Sententia diffinitiva contra Johannem Ladidaude et eius maritum super triginta solidis annui redditus. [26 février 1276] fo53

[227] CCXIX- Carta Guidonis de Etrysiaco militis. [18 mars 1288] fo53-53v ${ }^{\circ}$

[228] CCXX- Item carta de eodem. [1er avril 1288] fo53vo 54 
[229] - Carta Bernardi Torcoul presbiteri de Sanctis qui dedit nobis XXX solidos super decaniam de Sanctis quas acquisiuit prioratui de Sancto Salvatore quibus sit prior debet $^{196}$. [1185] f 54

[230] CCXXI- Carta de quibusdam terris apud Digia pro Galtero quondam abbate nostro. [mai 1246] fo $54 v^{\circ}$

[231] CCXXII- Carta Regnaudi Berart militis de quadam domo apud Erienciacum. [1233] $f^{\circ} 54 v^{\circ}$

[232] CCXXIII- Carta Guillelmi la quale de quinque solidis. [6 juin 1271] fo $54 v^{\circ}$

[233] CCXXIIII- Carta Hugonis domini de sancto Verano. [1285] f $54 v^{\circ}-55$

[234] CCXXV- Carta Guidonis curati de Escanno de triginti solidis super quamdam domo. [18 mai 1270] $f^{\circ} 55$

[235] CCXXVI- Carta Regnaudi curati de Luciaco super quamdam terra. [12 août 1285] $f^{\circ} 55-55 v^{\circ}$ deffectum cuiusdem domus que debebat edificare in dicta platea nostra. [15 novembre 1293] f $63 v^{\circ}-64$

719 [249] CCXXXX $^{201}$ - Litera de XV solidis censuales portantes laudes et ventas quos vendidit nobis Philippus de Defenso recipimus die dominica post kalendas maii. [juin $1268] f^{\circ} 64-64 v^{\circ}$

[250] CCXXXXI- Litera de permutacione facta inter nos et Petrum Morelli de terris, vineis, pratis quos et quas habebat apud Montem sancti Sulpicii ad terras nostras sitas 
apud Villam maris contentas in hac carta prout de verbo ad verbum permutatio continetur. [septembre 1251] f ${ }^{\circ} 64 v^{\circ}$

[251] CCXXXXII- Litera de iiii solidis super vineam de Migraine quos debet nobis Hugo de Planchiis. [31 octobre 1302] f $65-65 v^{\circ}$

[252] CCXXXXIII- Habemus Xxx solidos annui redditus super prioratum nostrum de Castellione in Bazeio pro xx solidis et pro duobus quartellus bladi quo tenet a nobis prior de Castellione. [9 novembre 1296] fo $65 v^{\circ}-66$

[253] -Carta Stephani Gordance et Deline eius uxoris ${ }^{202}$. [mai 1294] fo66-67v ${ }^{\circ}$

[254] -Carta Stephani Gordance et Deline eius uxoris ${ }^{203}$. [mai 1294] f $f^{\circ} 68-69$

[255] CCXXXXIIII- Carta de v solidis quod habemus apud Yranciacum super quandam domum sita iuxta domum dicti Puillet quos $\mathrm{v}$ solidos solebamus recipere super quandam vineam sitam in territorio de Valours. [25 septembre 1294] f $69-69 v^{\circ}$

[256] CCXXXXV- Carta Girardi de Monte clerici et Ysabellis eius uxor de centum et viginti quinque libris turonensium quas receperunt pro domo et vineis nostris de Monte. [mars 1269] f $69 v^{\circ}-70$

727 [257] $\mathrm{CCXXXXVI}^{204}$ - Litera de quibusdem domibus sitis retro domum fratrum minorum super quibus habemus xi libras et iii denarios recti census portantes laudes et ventas. [juillet 1250] $f^{\circ} 70$

258] CCXXXXVII- Carta de iiii libras quos habemus super domos et caueas que fuerunt Iohannis ducis et Iohanne eius uxor. [18 mars 1294] fo70-71

[259] CCXXXXVIII- Carta cognitionis de L solidis quos debet curatus de sancto Ferreolo. [24 août 1240] fo71

[260] -[sans titre] [20 juin 1270] f $71 v^{\circ}$

[261] CCXXXXIX- Litera de ix solidis quos dedit nobis Hugo de Cheuannis miles et assignauit super decimam de Maillieto. [avril 1226] $f^{\circ} 71 v^{\circ}$

732 [262] I ${ }^{205}$ - Carta domus nostre site in costerio sancti Amatoris. [24 mai 1297] fo72

[263] II- Ce est la chatre [sic] dou chastiaul de nostre maison de saint Ametre. [24 mai 1297] fo $72-73$

734 [264] III- Carta de centum solidos quos debent nobis liberi Guillermi Chometi. [10 avril 1297] fo73-74

[265] IIII- Ce est la lettre dou chastiaul de cens sous de tournois que li enfant Guillaume Chomaut nous doiuent. [21 mars 1296] fo $74-75 v^{\circ}$

[266] V- Cest la letre du chasteu daucerre de vi libres de pansion que Pierre Burcuiz et Aliz sa fame dorgi nous vendit. [29 février 1296] $f^{\circ} 75 v^{\circ}-77$

[267] VI- Litera de vi libris annue pansionis quos vendiderunt nobis heredes Petrus de Burcuy et Aelydis eius uxor. [23 mars 1297] f $77-78$ [268] VII- Carta de x libris quos debent liberi Nicholai Pedagerii. [27 avril 1297] fo78-79

[269] VIII- Ce est la chatre de x libris que li enfans Nicholas le Paagier nous doiuent sus le pre de Beauche. [27 avril 1297] fo $79-80 v^{\circ}$

[270] IX- Ce est la chatre dou chastiaul de c sous de pansion que Estiennes Desquam nou ha vendui. [22 mars 1296] fo $80 v^{\circ}-82$ 
[271] X- Litera de c solidis annue pensionis quos Stephanus de Escanno vendidit nobis super vineas suas sitas in territorio do bouton. [11 avril 1297] f f $^{\circ}-83$

[272] - Ce est la lettre de Pierre Troue et de sa fame de l souz de rente a paier la mitie a la mise aoust et lautre mitie a la chandeleuse ${ }^{206}$. [30 mars 1298] fo $83 v^{\circ}$

[273] XI- Litera de minagiis nostris de Sancto Saluatore que Hugo, Johannes et Stephanus de Foresta armigeri fratres inuadiauerunt nobis pro quibus receperunt $\mathrm{l} x$ libras. [10 novembre 1263] f f $83 v^{\circ}-84$

[274] XII- Litera Bernardi Caalon qui recognouit in iudicio quod domina de Foresta recipiebat in minagium Sancti Saluatoris pro quolibet bicheto vendito unam geloniam. [10 novembre 1263] ${ }^{207} f^{\circ} 84$

[275] XIII- Carta Galteri dicti Roidean qui recognouit coram se debere triginta telonias frumenti domine Elisabeth de Foresta in uilla sancto Saluatore. [décembre 1252] fo84

[276] XIIII- Littera Guillelmi de Noa, Milonis eius filii dicti parui regis et Robelini Paniere qui recognouerunt se debere domine de foresta unam teloniam de quolibet bicheto saliceto, bladi et leguminum mensuratorum ad bichetum dicte domine in uilla sancti Saluatoris et venditorum. [22 décembre 1253] fo $84-84 v^{\circ}$

[277] XV-Carta Guillelmi Porvein de sancto Saluatore qui recognouit in iudicio que nullus debebat habere mensuram nec mensurare nisi ad mensuram domine de foresta. [4 décembre 1253] f $84 v^{\circ}-85$ 

Ligneroiles et de tribus solidis de costumis predictis portantibus laudes et ventas. [mai 1227] $f^{\circ} 105$

771 [301] XXXVIII- Carta saluamenti auene de Nerone per nobis vendiderunt Symon de Gurgiaco et Adelina eius uxor. [12 octobre 1233] $f^{\circ} 105-105 v^{\circ}$

[290] XXVII- Ce est la letre de lamortissement de la vigne de Sommepree assise en la iustice iadis madame Agnes de Saint Verein dame despoisse. [octobre 1284] f $f^{\circ} 93 v^{\circ}$

[291] XXVIII- Carta de L libris quas habemus super celerariam de Yrenciaco. [9 novembre 1296] fo $94-94 v^{\circ}$

[292] XXIX- Ce est la chatre de VIII libres de tournois que Henris Forgemo nouz doit. [lun. 8 septembre 1309] fo $94 v^{\circ}-96$ et Johanne sa fame nous doient. [1er mars 1311] fo96-98

[294] XXXI- Cest la letre dou chateu daucerre de XL soulz de pansion que Ligiers Gariteuvax nos ha vendu. [9 mars 1311] fo $98-99 v^{\circ}$ Johenne sa fame nous doiuent. [13 avril 1310] $f^{\circ} 99 v^{\circ}-101$

[296] XXXIII- Cest la lettre de XX sous de rente que la fame feu Mariot de Camus nous ha bailliee tant pour $\mathrm{X}$ soulz que li diz Nariot et ele nous ont donne pour leur anniuersaire quant pour $X$ soulz de rente achat dauxerre. [30 novembre 1304] $f^{\circ} 101-102 v^{\circ}$

67 [297] XXXIIII- Ce est la lettre de la retraite que Adam de Mailli fit pour li et pour Jehan son frere de XL sous de rente que feu Guillaume li Bocuz iadis maris Agnes la Bocue hauoit achetez de Gautier dou Maigni et de Jaquete sa fame, li quel xl sous nous hont este assis, done et quite dou dit Adam pour cause de son anniuersaire chescun an faire en nostre eglise. [20 juillet 1295] $f^{\circ} 102 v^{\circ}-104$ doiuent chascun an de rente sus la place dou molin de roiau. [1er février 1307 ${ }^{209}$ $f^{\circ} 104-105$ ordei super terriis et costumis suis de Polliaco subtus [décembre 1235] fo105

[302] XXXIX- Carta saluamenti nostri de Soeriis per nobis dederunt Humbaudus de Corgiaco miles et Regina eius uxor. [23 juin 1277] f ${ }^{\circ} 105 v^{\circ}-106$

[303] XL- Carta vinee nostre de Poziaco quam dedit nobis Gaudricus capellanus sancti Lupi. [s.d.] $f^{\circ} 106-106 v^{\circ}$

[304] XLI- Carta domini Guillermi de Melloto qui dedit nobis LX solidos super preposituram sancti Prisci. [avril 1260] f $f^{\circ} 106 v^{\circ}$

[305] XLII- Carta de rebus quas habemus apud Gurgiacum quas dedit nobis Lambertus de sancto Petro clericus. [17 janvier 1268] f ${ }^{\circ} 106 v^{\circ}-107$

[306] XLIII- Carta de XL solidis assessis super unum sextarium bladi mosture et frumenti super molendinum nostrum de Peteraul et super census et costumas nostros quos habemus apud Venussiam et in finagio dicte uille. [12 novembre 1284] fo $107-108 v^{\circ}$ 
Bulletin du centre d'études médiévales d'Auxerre | BUCEMA , Collection CBMA $f^{\circ} 109-110 v^{\circ}$ pris de XXII libres. [6 mai 1311] fo $110 v^{\circ}-112$ décembre 1306] f $112-113 v^{\circ}$ debordis. [7 novembre 1312] f $f^{\circ} 113 v^{\circ}-114$ Blondelli apud Montem sancti Supplicii. [juillet 1271] fo $114-114 v^{\circ}$ sitas apud Montem sancti Supplicii. [24 mai 1298] fo $114 v^{\circ}-115 v^{\circ}$ novembre 1274] fo $115 v^{\circ}-116$ Mailliet. [4 janvier 1298] fo $116-117 v^{\circ}$ $f^{\circ} 118-119 v^{\circ}$ mai 1311] fo $119 v^{\circ}-121$ LX soulz. [8 août 1311] f ${ }^{\circ} 121-122$ libres. [24 mai 1311] f $f^{\circ} 122-123 v^{\circ}$ mai 1301] fo $123 v^{\circ}-125$ Renaut Reborssiau nous ha vendu. [17 novembre 1295] fo $125 v^{\circ}-127$

[307] XLIIII- Carta de plateis nostris que nunc est edificate in domibus situs iuxta portellum sancti Germani ex una parte et iuxta domum Dei ex altera quos tenent relicta Iohannis Maugart et eius filia pro quatuor solidis ad uitam. [27 juillet 1283] f ${ }^{\circ} 108 v^{\circ}-109$

[308] XLV- Ce est la letre dune maison que maistres Iofroiz de saint Priue nous vendit seant ou chatiau de saint Germain tenant a la maison iehanz du celier. [9 mai 1311]

[309] XLVI- Ce est la letre dou chatiau daucerre de une piece de vigne seant ou territorio et dou cry que Aliz fame iadis feu Guiot de Dauetry nous ha vendue pour le

[310] XLVII- Ce est la letre dou chasteu daucerre de XL soulz de pansion que estien Guiberz des Bourdes nous ha vendu sus la maison et sus plushueres héritages. [18

[311] XLVIII- Litera de XL solidis annue pansionis quos debet nobis Iohannes filius quondam defuncti Guichardi super domum et vineas que sunt Stephani Guiberti

[312] XLIX- Litera de terris nostris, pratis et vineis nostris quos dedit nobis Richerius

[313] L- Litera Richerii Blondelli qui dedit nobis istas res que continetur in hac carta

[314] LI- Litera Ysabellis relicte Iacobi de Briennone qui dedit nobis possessiones quas habebat ad Montem sancti Supplicii tam in vineis et pratis quam in terris arabilibus. [20

[315] LII- Ce est la letre du chateau daucerre de XL sous que Lambert feisanz de Maillot et Adeline sa fame nous venderint sus plusheurs terres et vignes assises oufinage de

[316] LIII- Carta de sede molendini siti iuxta pratum diderii. [1239] $f^{\circ} 117 v^{\circ}$

[317] LIIII- Ce est la letre dou chatau daucerre de quatre arpanz de vigne assis en lacroisete dou Vaus que Iehanz Troue et Iohanne sa fame nous ont vandu. [mai 1291]

[318] LV- Ce est la chartre du chatiau daucerre de une piece de vigne seant pres dela croysete de vaus que Jehanz Troue li einsnea et Margarete sa fame nos ont donnee. [29

[319] LVI- Ce est la chartre dou chatiau daucerre dune piece de vigne tenant a notre vigne de la croysete de vaus laquelle nous auons achetee de Iehannoz de Veroles pour

[320] LVII- Ce est la letre du chatiau daucerre dune piece de vigne tenant a notre vigne de la croysete que Iehanz Troues li einsnes et Marguerite sa fame nos ont vendu pour L

[321] LVIII- Ce est la letre du chatiau daucerre de vi libres de pansion que Pierres Cudayne et Isabeaus sa fame nous vendit sus ses vignes et sa maison de saint Geruais. [8

[322] LIX-Cest la letre dou chatau daucerre de xl soulz de pansion de Felise fame feu 
[323] LX-Ce est la letre dou chatau daucerre de lx soulz de pansion que Guiot li Buef et Adeline sa fame nous hont vendu sus la vigne de Mont blans. [8 décembre 1296] $f^{\circ} 127-128 v^{\circ}$

[324] LXI- Ce est la letre dou chatiau de quitance que Girart Pequaut et Berniers se freres nous ont fait de lor heritages. [26 mars 1312] f $128 v^{\circ}-131$

[325] LXII- Ce est la letre de ii pieces de preez que nos hauons sus la riuiere de beauche les quelles nous vendit Pierres Uiniau por le pris de lx libres. [31 mai 1299] f०131-132

[326] LXIII- Litera magistri Hugonis de Hermenco de ii peciis terre quarum una sita est in finagio des conches alia usque molendina de Esquere. [3 janvier 1302] fo132-133

[327] LXIIII- Ce est la letre dou chatiau daucerre de xl libres de pansion que Iehanz Emarz et Ysabeau sa fame nous deuoint sus plushuers vignes et sus sa maison. [19 octobre 1305] f $f^{\circ} 133-134 v^{\circ}$

[328] LXV- Ce est la letre de xi libres de pansion que Iohannoz Emarz nous doit sur vignes et plusheurs heritages. [19 octobre 1305] fo $134 v^{\circ}-136 v^{\circ}$

Les cartulaires des dépendances

Quatre des dépendances de Saint-Germain conservent des documents appelés improprement- cartulaires dans les classements d'archives. Il s'agit de dossiers de chartes réalisés entre 1629 et 1665, le plus souvent à partir de cartulaires.

Decize

Il s'agit en fait de trois feuillets de papier copiés au XVII ${ }^{\mathrm{e}}$ siècle portant transcription de sept bulles pontificales de confirmation du temporel de Saint-Germain dans lesquelles apparaît la dépendance de Saint-Pierre de Decize. Ces feuillets appartenaient sans doute à un cahier plus important car le dernier acte est tronqué. Les bulles portent sur la période 1186-1256 et sont toutes copiées d'après le grand cartulaire de Saint-Germain dans l'ordre de ce dernier. L'appellation de cartulaire est ici impropre.

Manuscrit : AD Nièvre, H 317, Stein $\mathrm{n}^{\circ}$ 1129. Fragment du bullaire de Saint-Germain concernant le prieuré Saint-Pierre de Decize, dit Cartulaire du prieuré de Decize.

Moutiers

Un cahier de quarante pages qualifié parfois de cartulaire comporte des copies de chartes concernant l'une des premières dépendances de Saint-Germain. Celles-ci sont avant tout des baux, des prises de possession du prieuré et des actes portant trace des conflits que Moutiers dut soutenir entre 1413 et 1660 . Aucun document copié n'est antérieur à la bulle de réunion de la dépendance à la fabrique de l'abbaye en 1413 et le dernier copiste signale que cette union à la fabrique eut lieu «il y a environ deux cent cinquante ans ». Ce qui peut être assimilé à un cahier-cartulaire a donc été achevé vers 1660-1665. Nous sommes là exactement à l'époque des Mauristes dom Cotron et dom Viole dont les travaux sur Saint-Germain sont peut-être à l'origine de l'établissement de ce recueil. Cette hypothèse permettrait de mieux comprendre pourquoi certains actes très indirectement liés à Moutiers ont été transcrits ici par une main fort proche de celle qui a noirci l'essentiel des volumes que dom Viole consacra à son Histoire d'Auxerre.

3 Manuscrit : AD Yonne, H 1058. Aumônerie de Moutiers, cartulaire. Saint-Florentin

Il s'agit d'un cahier de 22 chartes, réalisé dans le premier tiers du XVII ${ }^{e}$ siècle et puisé à trois cartulaires, chaque actes comportant sa source à la fin de copie: celui de 
Pontigny, le grand cartulaire de Saint-Germain et le cartulaire de Saint-Florentin. Celui-ci, aujourd'hui perdu, comportait 42 feuillets et avait été composé à la demande du prieur de Saint-Florentin peu après 1629 par le cellerier de Saint-Germain. Ce cahier-cartulaire ne présente ni préambule, ni marque d'authentification notariale. Sous la même cote, ont été conservées sept copies notariées d'actes figurant, pour six d'entre eux, dans le cartulaire. Toutes ces copies portent la mention «Jehan prévost conseiller du roi au bailliage et siège présidial d'Auxerre commissaire de par nos seigneurs au grand conseil pour l'exécution de nos arrêts du 11 may 1637, au vu de l'original ».

Ce cahier comporte treize feuillets papier, composé d'un binion imparfait (manque le deuxième feuillet), d'un quaternion et d'un bifeuillet inséré plié entre le quaternion et le binion extérieur. Il conserve copie de vingt-deux chartes datées de 1035-1052 à 1228 et transcrites sans ordre particulier. Elles se répartissent chronologiquement de la manière suivante : XI ${ }^{\mathrm{e}}$ siècle (1), XII ${ }^{\mathrm{e}}$ siècle (12), XIII ${ }^{\mathrm{e}}$ siècle (9).

Manuscrit : AD Yonne, H 1068. Recueil de chartes du prieuré de Saint-Florentin.

Édition partielle : M. QUANTIN, Cartulaire général de l'Yonne, 2 vol., Auxerre, 1854-1860.

Saint-Léger-de-Champeaux

Manuscrit in quarto de 232 feuillets papier composé en 1647 par Simon Rouyer, notaire tabellion royal, lieutenant au bailliage et marquisat de Mirebeau, procureur d'office aux terres et seigneuries du prieuré de Saint-Léger.

Ce cartulaire rassemble 73 actes globalement ordonnés selon la succession chronologique entre 1258 et 1637 qui se détaille ainsi : XIII ${ }^{\mathrm{e}}$ siècle (13), XIV ${ }^{\mathrm{e}}$ siècle (26), $\mathrm{XV}^{\mathrm{e}}$ siècle (16), XVI ${ }^{\mathrm{e}}$ siècle (13), XVII ${ }^{\mathrm{e}}$ siècle (5).

Parmi les quatre cartulaires connus des dépendances auxerroises, il est le seul à être véritablement digne de ce nom.

Manuscrit: AD Côte d'Or, $38 \mathrm{H}$, cart. $\mathrm{n}^{\circ} 230$, Stein $\mathrm{n}^{\circ}$ 3466. Cartulaire du prieuré de Saint-Léger-de-Champeaux.

\section{BIBLIOGRAPHIE}

N. Deflou-LeCA, « L'élaboration d'un cartulaire au XIII ${ }^{\mathrm{e}}$ siècle : le cas de Saint-Germain

d'Auxerre ", in Revue Mabillon, n.s., 8 (1997), p. 183-207.

N. Deflou-LeCA, saint-Germain d'Auxerre et ses dépendances ( $\mathrm{V}^{\mathrm{e}}$-XIII ${ }^{\mathrm{e}}$ siècle). Un monastère dans la société du haut Moyen Âge, Saint-Étienne, CERCOR, (Travaux et recherches), sous presse.

\section{NOTES}

1.. Voir l'édition et la traduction de ce préambule dans N. DefLOU-LECA, « L'élaboration d'un cartulaire au XIII e siècle : le cas de Saint-Germain d'Auxerre », in Revue Mabillon, n.s., 8 (1997), p. 207. 
2.. Ceux de La Charité (R. de LESPINASSE, Cartulaire de La Charité-sur-Loire, Nevers-Paris, 1887) ou de Pontigny font figure d'exceptions (M. GARRIGUES, Le premier cartulaire de l'abbaye cistercienne de Pontigny (XII ${ }^{e}$-XIII ${ }^{e}$ siècles), Paris, 1981 (Coll. de textes inédits sur l'histoire de France).

3.. Cette table dresse une liste de tous les actes du grand cartulaire de l'abbaye. Établie à partir de la table du manuscrit complétée lorsqu'elle était lacunaire, elle reprend strictement l'ordre du codex et reproduit la classification en chapitres lorsqu'elle existe, c'est-à-dire pour la première phase de rédaction, transcrite après 1266 par le scribe anglais Walter. Pour faciliter leur identification les actes ont été numérotés dans leur ordre d'apparition au fil du codex. Chaque numéro est porté entre crochets droits devant l'intitulé de l'acte. La numérotation en chiffres romains qui la suit reproduit, lorsqu'elle existe, celle utilisée dans la table du cartulaire (fol. 1-5). Foliotation et dates des actes ont été rajoutés, en italique pour les premiers et entre crochets droits pour les seconds. Nous avons indiqué en note les références des originaux lorsqu'ils existent, des copies, manuscrites ou imprimées, et des mentions que nous avons pu consulter. 4.. AD Yonne, H 984 (copies datées de 1607 et 1676) ; dom V. cotron, Chronicon augustissimi ac perillustris coenobii sancti Germani Altissiodorensis..., Auxerre, 1652, Auxerre, B.M., ms. 167 G (anc. 148), p. 867 (noté Cotron) ; dom G. VIOLE, Historia abbatum monasterii sancti Germani Autissiodorensis, in Mémoires sur l'histoire du diocèse d'Auxerre, Auxerre, vers 1640, Auxerre, B.M., ms. 154 G (anc. 138), p. 219-222 (noté violE) ; Gallia Christiana (noté G.C.), XII col. 182-183, n 121 ; M. QUANTIN, Cartulaire général de l'Yonne, 2 vol., Auxerre, 1854-1860, I, nº 327 (désormais noté QUANTIN I ou II).

5.. AD Yonne, H 984 (copies datées de 1607 et 1676) ; VIOLE, ms. 154, p. 222-228 ; W. WIEDERHOLD, Papsturkunden in Frankreich, vol. I, Vaticano, 1985, V, nº 27 ; mention dans QUANTIN, I, n 327.

6.. AD Yonne, H 984 (copies datées de 1607 et 1676) ; Copie en 1676 par Louis-Noël Damy, AD Yonne, H 1193 ; QUANTIN, II, n 376 ; COTRON p. 903 ; mention Ph. JAFFÉ, Regesta pontificum romanorum, II, Lipsiae, 1888, $\mathrm{n}^{\circ} 16231$.

7.. AD Yonne, H 984 (copies datées de 1607 et 1676) ; Copie en 1676 par Louis-Noël Damy, AD Yonne, H 1193 ; WIEDERHOLD, vol. I, V, nº 157 ; V-B. HENRY (Histoire de l'abbaye de Saint-Germain d'Auxerre, Auxerre, 1853, p. 225-231) en donne une traduction. Mentions dans QUANTIN, II, $\mathrm{n}^{\circ} 376$ et Ph. JAFFÉ, II, nº 17140.

8.. AD Yonne, H 984 (copies dont deux datées de 1607 et 1676) ; Copie partielle au XV $\mathrm{X}^{\mathrm{e}}$ Paris, BnF, ms. fr. 18693, p. 457-458; COTRON, p. 918, d'après LE CART ET YEPER, Chronique de l'ordre de St Benoist, 1609-1615, t. 4, p. 35 ; MIGNE, P.L., 214, col. 241-244 ; Mention dans QUANTIN, II, n 376 ; L-G. BRÉQUIGNY, Table chronologique des diplômes, chartes..., IV, p. 250.

9.. QUANTIN, I, nº 379 ; JAFFÉ, n 10045.

10.. AD Yonne, H 988 (copie XVIIe), H 984 (copie XVIIIe) ; COTRON, p. 894 ; WIEDERHOLD, vol. I, V, n 132 .

11.. AD Yonne, H 988 (copie XVIIe), H 984 (copie XVIIIe) ; COTRON p. 893 ; WIEDERHOLD, vol. $\mathrm{I}, \mathrm{V}, \mathrm{n}^{\circ} 129$.

12.. COTRON, p. 976 ; M. QUANTIN, Recueil des pièces pour faire suite au cartulaire général de l'Yonne XIII siècle, Auxerre, 1873, III, n 547 (désormais noté QUANTIN, III).

13.. QUANTIN, II, $\mathrm{n}^{\circ} 366$; mentions COTRON, p. 890 ; J. LEBEUF, Mémoires concernant l'histoire civile et ecclésiastique d'Auxerre et de son ancien diocèse, 4 vol., 1743, réed. Auxerre-Paris, 1848-1855, I, 325 (noté LEBEUF) ; analyse AD Nièvre, H 317 ; JAFFÉ, II, nº 15852.

14.. COTRON, p. 914; WIEDERHOLD, vol. I, V, nº 158. 
15.. WIEDERHOLD, vol. I, V, $\mathrm{n}^{\circ} 160$.

16.. COTRON, p. 14 ; QUANTIN, II, nº 451 ; mention JAFFÉ, II, nº 17133.

17.. Copie AD Nièvre, H 317 ; COTRON, p. 932.

18. COTRON, p. 933.

19.. COTRON, p. 918.

20.. COTRON, p. 919 ; Analyse AD Nièvre, H 317.

21.. COTRON, p. 915; WIEDERHOLD, vol. I, V, nº 162.

22.. COTRON, p. 859. XXX = XXVIII (fol. $15 \mathrm{v}^{\circ}$ ).

23. LEBEUF, IV, 186. Le copiste de la table a bouleversé l'ordre suivi dans la transcription des chartes pour les numéros 28 à 30. XXVIII $=\operatorname{XXIX~}\left(\right.$ fol. $\left.15 \mathrm{v}^{\circ}\right)$.

24.. QUANTIN, I, $\mathrm{n}^{\circ}$ 190. XXIX $=$ XXX (fol. $\left.15 \mathrm{v}^{\circ}\right)$.

25.. WIEDERHOLD, vol. I, $\mathrm{V}, \mathrm{n}^{\circ} 141$.

26.. =XXXII, C'est une erreur du décorateur chargé de placer les nombres rubriqués. COTRON, p. 889 ; WIEDERHOLD, vol. I, V, n 71.

27. WIEDERHOLD, vol. I, V, $\mathrm{n}^{\circ} 155 .=$ XXXIII. Idem.

28. COTRON, p. 890 ; WIEDERHOLD, vol. I, $\mathrm{V}, \mathrm{n}^{\circ} 128$.

29.. AD Nièvre, H 317 ; COTRON, p. 895 ; WIEDERHOLD, vol. I, V, nº 131.

30.. Analyse AD Nièvre, H 317.

31.. Copie XVe d'après l'original, Paris, BnF, ms. fr. 18693, p. 457 ; WIEDERHOLD, vol. I, V, $\mathrm{n}^{\circ} 154$.

32.. WIEDERHOLD, vol. I, $\mathrm{V}, \mathrm{n}^{\circ} 163$.

33.. COTRON, p. 883 ; WIEDERHOLD, vol. I, V, nº 62.

34.. COTRON, p. 895 ; WIEDERHOLD, vol. I, $\mathrm{V}, \mathrm{n}^{\circ} 121$.

35.. QUANTIN, II, $\mathrm{n}^{\circ} 367$; COTRON, p.891; JAFFÉ, II, n 15859.

36.. BERGER, Les registres d'Innocent IV, III, $\mathrm{n}^{\circ} 6554$.

37.. BERGER, II, $\mathrm{n}^{\circ} 6390$.

38.. Analyse COTRON, p. 985.

39.. Analyse COTRON, p. 985.

40.. Analyse COTRON, p. 985.

41.. Analyse COTRON, p. 985 ; BOUREL DE LA RONCIÈRE, Les registres d'Alexandre IV, I, n 1292.

42.. Analyse COTRON, p. 985 ; BOUREL DE LA RONCIÈRE, I, nº 1292.

43.. Analyse COTRON, p. 988.

44.. Cf infra $n^{\circ} 348,349$.

45.. Le copiste de la table a omis d'indiquer cette dernière charte, transcrite de la main de Walter après 1266 . Berger, IV, $\mathrm{n}^{\circ} 6389$.

46. Main différente, dont le tracé des lettres est plus gothique. L'ornementation n'a pas été réalisée mais la place des lettres et de nombres rubriquées a été laissée dans cette intention.

47.. Autre main.

48.. AD Yonne, H 1010 ; Paris, BnF, coll. Clairambault 994, p. 285 , coll. Bourgogne 69, fol. 34 ; COTRON, p. 672 ; QUANTIN, I, n 52 ; Recueil des Historiens des gaules et de la France (noté RHGF), VIII, 273 ; GIRY, A., Recueil des actes de Charles le Chauve, Paris, 1955, n² 27 (noté GIRY).

49.. AD Yonne, H 1010, 2 ; COTRON, p. 589 ; QUANTIN, I, $n^{\circ} 23$.

50.. AD Yonne, H 1010 ; H 988, nº 69 ; H 985 ; COTRON, p. 620 ; VIOLE, ms. 154, p. 31 ; Paris, BnF, coll. Clairambault 994, p. 287, coll. Bourgogne 69, fol. 35, coll. Duchesne 57, fol. 
122 ; LEBEUF, IV, $\mathrm{n}^{\circ} 8$; QUANTIN, I, $\mathrm{n}^{\circ} 37$; RHGF, VIII, 155 ; GIRY, $\mathrm{n}^{\circ} 214$; A. STOCLET, Immunes ab omni teloneo. Étude de diplomatique, de philologie et d'histoire sur l'exemption des tonlieux au haut Moyen Âge et spécialement sur la Praeceptio de navibus, Bruxelles-Rome, 1999, p. 400-401 (Institut historique belge de Rome bibliothèque, 14).

51.. AD Yonne, H 1010 ; COTRON, p. 616 ; VIOLE, ms. 154, p. 34 ; Paris, BnF, coll. Clairambault 994, p. 289, coll. Bourgogne 69, fol. 35 ; LEBEUF, IV, nº ; QUANTIN, I, n³6 ; RHGF, VIII, 147 ; GIRY, $\mathrm{n}^{\circ} 200$.

52.. AD Yonne, H 1010 ; COTRON, p. 629 ; VIOLE, ms. 154, p. 36 ; Paris, BnF, coll. Clairambault 994, p. 290, coll. Bourgogne 69, fol. 35 v $^{\circ}$; QUANTIN, I, n 40 ; GIRY, nº 235. 53.. AD Yonne, H 1010 ; COTRON, p. 651 ; VIOLE, ms. 154, p. 52 ; Paris, BnF, coll. Clairambault 994, p. 291, coll. Duchesne 57, fol. 123, coll. Baluze, 142, fol. 174, coll. Bourgogne 69, fol. 36 ; LEBEUF, IV, $\mathrm{n}^{\circ} 10$; QUANTIN, I, n 42 ; RHGF, VIII, 184 ; GIRY, $\mathrm{n}^{\circ} 261$. 54.. AD Yonne, H 1010 ; COTRON, p. 680 ; VIOLE, ms. 154, p. 108 ; Paris, BnF, coll. Baluze 142, p. 175, coll. Duchesne 57, fol. 124 ; LEBEUF, IV, $\mathrm{n}^{\circ} 11$; QUANTIN, II, $\mathrm{n}^{\circ} 7$; RHGF, IX, 3 ; GRAT, F., Recueil des actes de Louis le Bègue..., Paris, 1978, ${ }^{\circ} 6$.

55.. AD Yonne, H 1010 ; COTRON, p. 720 ; LEBEUf, IV, $\mathrm{n}^{\circ} 12$; QUANTIN, I, $\mathrm{n}^{\circ} 68$; Ph. LAUER, Recueil des actes de Charles le Simple, Paris, 1949, $\mathrm{n}^{\circ} 38$.

56.. AD Yonne, H 1010 ; COTRON, p. 608, Paris, BNF, coll. Clairambault 994, p. 295, coll. Bourgogne 69, fol. 36 ; VIOLE, ms. 154, p. 28 ; QUANTIN, I, nº 34 ; GIRY, n 156.

57.. AD Yonne, H 1010 ; COTRON, p. 618 ; Paris, BnF, coll. Clairambault 994, p. 296, coll. Bourgogne 69, fol. 36, coll. Duchesne 55, fol. 125 ; VIOLE, ms. 154, p. 30 ; QUANTIN, I, n³ 38 ; GIRY, $\mathrm{n}^{\circ} 215$.

58.. AD Yonne, H 1010 ; COTRON, p. 627 ; Paris, BnF, coll. Clairambault 994, p. 297, coll. Bourgogne 69, fol. 37 ; VIOLE, ms. 154, p. 35; LEBEUF, IV, nº 9 ; QUANTIN, I, n 39 ; RHGF, VIII, $168 ;$ GIRY, n²33.

59.. AD Yonne, H 1010 ; QUANTIN, I, $\mathrm{n}^{\circ} 41$; GIRY, $\mathrm{n}^{\circ} 262$.

60.. AD Yonne, H 1010 ; COTRON, p. 658 ; VIOLE, ms. 154, p. 54 ; Paris, BnF, coll. Clairambault 994, p. 300, coll. Baluze 142, fol. 174, ms. lat. 12778, fol. 226; QUANTIN, I, $\mathrm{n}^{\circ} 47$; RHGF, VIII, 196 ; GIRY, $\mathrm{n}^{\circ} 288$.

61.. QUANTIN, I, $\mathrm{n}^{\circ} 56$; F. GRAT et alii, Recueil des actes de Louis II le Bègue, Louis III et Carloman II, rois de France (877-884), Paris, 1978, $\mathrm{n}^{\circ} 61$.

62.. AD Yonne, H 1010 ; COTRON, p. 770 ; QUANTIN, I, n 82 ; RHGF, X, 562 ; MABILLON, De re diplomatica, p. 578. W.M. NEWMAN, Catalogue des actes de Robert II, roi de France, Paris, 1937, $\mathrm{n}^{\circ} 7$.

63.. GIRY, $\mathrm{n}^{\circ} 214$; A. STOCLET, Immunes ab omni teloneo..., 1999, p. 400-401.

64.. AD Yonne, H 1010 ; COTRON, p. 640 ; VIOLE, ms. 154, p. 43 ; Paris, BnF, coll.

Clairambault 994, p. 306 ; QUANTIN, I, n 46 ; RHGF, VIII, 189 ; Gallia Christiana, XII, 97-99 ; GIRY, $n^{\circ} 269$.

65.. AD Yonne, H 1010, H 985, H 988 ; COTRON, p. 684 ; VIOLE, ms. 154, p. 64 ; Paris, BnF, coll. Clairambault 994, p. 309, coll. Du chesne 57, fol. 77, 125 ; MABILLON, De re dipl., p. 550-552; QUANTIN, I, $\mathrm{n}^{\circ} 57$; RHGF, IX, 19 ; GRAT, $\mathrm{n}^{\circ} 77$.

66.. AD Yonne, H 1010 ; COTRON, p. 606 ; QUANTIN, I, n 59 ; RHGF, IX, p. 352 ; Kehr, n 145. 67.. AD Yonne, H 1010 ; COTRON, p. 704 ; VIOLE, ms. 154, p. 92 ; Paris, BnF, coll. Clairambault 994, p. 323 ; QUANTIN, I, n 61 ; RHGF, IX, 9 ; G. Tessier, Recueil des actes d'Eudes..., Paris, 1967, nº12. 
68.. AD Yonne, H 1010 ; COTRON, p. 707 ; Paris, BnF, coll. Clairambault 994, p. 325, coll. Bourgogne 69, fol. 38 ; QUANTIN, I, n 62 ; Tessier, $\mathrm{n}^{\circ} 11$; A. STOCLET, Immunes ab omni teloneo... , 1999, p. 431-432.

69.. AD Yonne, H 1010, H 985, H 988 ; COTRON, p. 748 ; Paris, BnF, coll. Clairambault 994, p. 327, coll. Duchesne 57, fol. 129 ; QUANTIN, I, n 72 ; Ph. LAUER, Recueil des actes de Louis IV, Paris, $1914, \mathrm{n}^{\circ} 3$.

70.. AD Yonne, H 1010 ; COTRON, p. 780 ; QUANTIN, I, $\mathrm{n}^{\circ} 84$; mention dans NEWMAN, $\mathrm{n}^{\circ} 35$.

71.. QUANTIN, I, n $14 ;$ RHGF, VI, p. 488.

72. Écrit d'une autre main moderne. Original AD Yonne, H 984 ; QUANTIN, I, n 45 ; M. COURTOIS, M. PARISSE, Les actes originaux conservés dans le département de l'Yonne, Nancy, $1989, \mathrm{n}^{\circ} 7$ (noté COURTOIS, PARISSE).

73.. Copie libre s. d. AD Yonne, H 989 ; LEBEUf, IV, $n^{\circ} 21$; QUANTIN, I, $n^{\circ} 132$.

74.. LEBEUF, IV, $\mathrm{n}^{\circ} 38$; QUANTIN, I, $\mathrm{n}^{\circ} 286$.

75.. LEBEUF, IV, $\mathrm{n}^{\circ} 45$; QUANTIN, $\mathrm{I}, \mathrm{n}^{\circ} 373$.

76.. LEBEUF, IV, $\mathrm{n}^{\circ} 48$; QUANTIN, II, $\mathrm{n}^{\circ} 89$.

77.. Original AD Yonne, H 1159.

78.. Original AD Yonne, H 1159.

79.. QUANTIN, I, $\mathrm{n}^{\circ} 266$ (daté vers 1147) et II, n 51 (daté entre 1142 et 1168). Il s'agit de la même charte, un seul mot diffère. Dans se première version M. Quantin a transcrit le verbe du protocole au singulier (volo) et dans la seconde un pluriel (volumus).

80.. QUANTIN, III, $\mathrm{n}^{\circ} 343$.

81.. Original, AD Yonne, H 999.

82.. Copie réalisée en 1659 par Louis Noël Damy (A.D Yonne H 1166) ; LEBEUF, IV, $\mathrm{n}^{\circ} 77$.

83.. QUANTIN, II, $n^{\circ} 478$, précise avoir transcrit la charte depuis le grand cartulaire et signale l'original autrefois scellé (AD Yonne, H 1166). La liasse correspondant à cette cote ne comporte que des copies notariées signées faites à partir des originaux en date de 1659.

84.. LEBEUF, IV, $\mathrm{n}^{\circ} 97$.

85.. Mention QUANTIN, III, $\mathrm{n}^{\circ} 491$.

86. ibid.

87.. Original AD Yonne, fonds de Saint-Marien, H 1215.

88. Copie collationnée en 1685, AD Yonne, H 1043.

89. Copie collationnée en 1685, AD Yonne, H 1043.

90.. LEBEUF, IV, $\mathrm{n}^{\circ} 31$; QUANTIN, I, $\mathrm{n}^{\circ} 216$;.

91.. LEBEUF, IV, $\mathrm{n}^{\circ} 43$; QUANTIN, $\mathrm{I}, \mathrm{n}^{\circ} 328$.

92.. LEBEUF, IV, $\mathrm{n}^{\circ} 50$.

93.. LEBEUF, $\mathrm{IV}, \mathrm{n}^{\circ} 56$.

94.. LEBEUF, IV, $\mathrm{n}^{\circ} 65$; QUANTIN, II, $\mathrm{n}^{\circ} 214$.

95.. QUANTIN, II, $\mathrm{n}^{\circ} 213$.

96.. QUANTIN, II, $\mathrm{n}^{\circ} 248$.

97.. QUANTIN, II, $\mathrm{n}^{\circ} 249$.

98. LEBEUF, IV, $\mathrm{n}^{\circ} 53$; QUANTIN, I, n³65 (daté entre 1154 et 1161) et II, nº 132 (daté de 1163).

99.. QUANTIN, III, $\mathrm{n}^{\circ} 8$.

100.. QUANTIN, III, $\mathrm{n}^{\circ}$ 90. Acte réitéré en 1212 (Petit cartulaire, $\mathrm{n}^{\circ}$ 81)

101.. LEBEUF, IV, $\mathrm{n}^{\circ} 125$. 
102.. LEBEUF, IV, $\mathrm{n}^{\circ} 136$.

103.. QUANTIN, III, $\mathrm{n}^{\circ} 226$.

104.. LEBEUF, IV, $\mathrm{n}^{\circ} 143$.

105.. Indication du chiffre seul, le texte n'a pas été transcrit bien que la place ait été laissée en blanc.

106.. Même procédé mais ici la place est occupée par une courte charte écrite en écriture cursive et portant cette indication en marge.

107.. LEBEUF, IV, $\mathrm{n}^{\circ} 167$.

108.. Original, AD Yonne, fonds de l'abbaye de Pontigny, H 1409 ; QUANTIN, I, $n^{\circ} 171, \mathrm{M}$. GARRIGUES, Le premier cartulaire de l'abbaye cistercienne de Pontigny (XII ${ }^{e}$-XIII ${ }^{e}$ siècles), Paris, (coll. de textes inédits sur l'histoire de France). 1981, n¹01, p. 171-172 (noté GARRIGUES). 109.. LEBEUF, IV, $\mathrm{n}^{\circ} 77$ bis ; QUANTIN, II, $\mathrm{n}^{\circ} 250$. Les deux éditeurs ont commis la même erreur de datation (1175 au lieu de 1165), à cause d'une mauvaise lecture de la correction maladroite du copiste Walter.

110.. LEBEUF, IV, $\mathrm{n}^{\circ} 57$.

111.. L'original est une notice en forme de chirographe AD Yonne, fonds de Pontigny, $\mathrm{H}$ 1409 ; QUANTIN, II, nº 437.

112.. Une charte donnée par l'abbé de Cîteaux et portant sur le même litige est conservée en original (AD Yonne, fonds de Pontigny, H 1506).

113.. Original AD Yonne, fonds de Saint-Germain, H 1129.

114.. Original AD Yonne, fonds de Pontigny, H 1506.

115.. En marge.

116. QUANTIN, III, $\mathrm{n}^{\circ} 410$.

117. QUANTIN, III, $\mathrm{n}^{\circ} 416$.

118. LEBEUF, IV, $\mathrm{n}^{\circ} 185$.

119. QUANTIN, III, $\mathrm{n}^{\circ} 355$ (édition partielle).

120.. Ajouté par une autre main, de même que la copie de la charte.

121.. LEBEUF, IV, $\mathrm{n}^{\circ} 46$; QUANTIN, II, $\mathrm{n}^{\circ} 98$.

122.. Charte originale en forme de chirographe, $\mathrm{AD}$ Yonne, fonds de l'abbaye de Reigny, H 1588 ; QUANTIN, II, n 191.

123.. QUANTIN, II, $\mathrm{n}^{\circ} 190$.

124.. QUANTIN, II, $\mathrm{n}^{\circ}$ 286. La référence donnée par Quantin (fol. 78) est erronée puisqu'elle renvoie à un folio blanc, l'acte figure au folio 73.

125.. QUANTIN, II, $\mathrm{n}^{\circ} 179$.

126.. Copie reprise dans un acte daté du 24 janvier 1469, AD Yonne, H 1177.

127.. QUANTIN, III, $\mathrm{n}^{\circ} 151$.

128.. QUANTIN, III, $\mathrm{n}^{\circ} 463$.

129.. Ajout d'une autre main.

130.. QUANTIN, II, $\mathrm{n}^{\circ} 39$.

131.. Copie XV ${ }^{\mathrm{e}}$, Paris, BnF, ms. fr. 18693, p. 453-455.

132.. Copie $X V^{\mathrm{e}}$, Paris, BnF, ms. fr. 18693, p. 455-457.

133.. Seul le titre rubriqué est copié dans le cartulaire.

134.. QUANTIN, II, $\mathrm{n}^{\circ} 258$.

135.. Mention dans QUANTIN, II, $\mathrm{n}^{\circ} 258$.

136.. QUANTIN, II, $\mathrm{n}^{\circ} 52$.

137.. QUANTIN, I, $\mathrm{n}^{\circ} 219$.

138.. QUANTIN, II, $\mathrm{n}^{\circ} 65$. 
139.. QUANTIN, I, $\mathrm{n}^{\circ} 281$.

140.. Copie en 1676 par Louis-Noël Damy, AD Yonne, fonds de Saint-Germain, H 1193, QUANTIN, II, $\mathrm{n}^{\circ} 388$.

141.. Copie en 1676 par Louis-Noël Damy, AD Yonne, fonds de Saint-Germain, H 1193, QUANTIN, I, $\mathrm{n}^{\circ} 317$.

142.. QUANTIN, I, $\mathrm{n}^{\circ} 285$.

143.. Original, AD Yonne, fonds de Saint-Germain, H 1192 ; QUANTIN, III, nº 316.

144.. Copie libre s.d., AD Yonne, fonds de Saint-Germain, H 1124.

145.. Conservation de deux originaux l'un en écriture de charte, l'autre en cursive, ainsi que deux copies collationnées, datées de 1685 et 1688 et une copie libre partielle sans date, AD Yonne, fonds de Saint-Germain, H 1192 ; QUANTIN, III, n 498 (édition partielle). 146.. Copies collationnées en 1685 et 1688, AD Yonne, fonds de Saint-Germain, H 1192. 147.. Original, AD Yonne, fonds de Saint-Germain, H 1192 ; QUANTIN, I, nº 89 ; H. ARBOIS DE JUBAINVILLE, Histoire des ducs et des comtes de Champagne depuis le VI siècle jusqu'à la fin du $X^{e}$ siècle, 7 vol., Paris, 1859-1869, I, nº 41, p. 477-478 ; COURTOIS, PARISSE, $\mathrm{n}^{\circ} 15$.

148. Deux copies s.d., AD Yonne, fonds de Saint-Germain, H 1072 ; QUANTIN, II, $\mathrm{n}^{\circ} 74$.

149.. Copie s.d., AD Yonne, fonds de Saint-Germain, H 1071, QUANTIN, II, $\mathrm{n}^{\circ} 120$.

150.. Cartulaire de la pitencerie de l'abbaye, Auxerre, B.M., ms. 162, fol. 44 ; QUANTIN, II, $\mathrm{n}^{\circ} 347$.

151.. QUANTIN, I, $\mathrm{n}^{\circ} 138$.

152.. Le scribe Walter a copié un acte en ménageant les espaces des titres et des initiales à rubriquer. Celui-ci a bien porté un $\mathrm{G}$ précédé du numéro de l'acte $(\mathrm{V})$, mais n'a inscrit que vacat à la place du titre alors que la charte était soigneusement rayée ligne à ligne.

153.. Cart. de la Pitencerie (Auxerre, B.M., ms. 162, $\mathrm{n}^{\circ}$ 221, fol. 51) ; Mention QUANTIN, II, $\mathrm{n}^{\circ} 347$.

154.. Chiffre VII omis.

155.. LEBEUF, IV, $\mathrm{n}^{\circ} 102$.

156.. La traduction d'une charte sur le même sujet est copiée par Edme Leboyt, notaire, en 1684, ADYonne, fonds de Saint-Germain, H 1152.

157.. Original, AD Yonne, fonds de Saint-Germain, H 1146 ; QUANTIN, III, nº 83.

158.. Original, AD Yonne, fonds de Saint-Germain, H 1146.

159.. Original, AD Yonne, fonds de Saint-Germain, H 1146.

160.. Original, AD Yonne, fonds de Saint-Germain, H 1146.

161.. Original, AD Yonne, fonds de Saint-Germain, H 1169.

162.. Copie libre s.d. AD Yonne, fonds de Saint-Germain, H 1078 ; Cart de la pitencerie fol. $2, \mathrm{n}^{\circ} 7$.

163.. Original, AD Yonne, fonds de Saint-Germain, H 1146.

164.. Ed. partielle QUANTIN, III, $\mathrm{n}^{\circ} 613$.

165.. COTRON, p. 992-993.

166.. La charte n'a pas été copiée. Le scribe a ajouté vacat per permutationem.

167.. M. QUANTIN, III, $\mathrm{n}^{\circ} 559$ (avec une erreur de foliotation dans la référence). Cf supra charte $n^{\circ} 53$.

168. . Cf supra $\mathrm{n}^{\circ} 53$.

169.. LEBEuf, IV, $\mathrm{n}^{\circ}$ 188. Cartulaire de la ville d'Auxerre, fol. 27 et suiv. (A. M. Auxerre). 170.. QUANTIN, III, $\mathrm{n}^{\circ} 561$. 
171.. L'acte est daté du mardi après la saint Hilaire. La datation est ici résolue en prenant pour référence l'évêque de Poitiers.

172.. Chaque acte comporte entre parenthèses sa datation résolue, en italique sa foliotation. La numérotation, portée entre crochets droits a été établie pour faciliter le renvoi aux actes. Les numérotations portées en chiffres romains sont celles du cartulaire. Les majuscules des noms propres ont été restituées.

173.. M. QUANTIN, Recueil des pièces pour faire suite au cartulaire général de l'Yonne XIII ${ }^{e}$ siècle, Auxerre, 1873, III, nº 188 (désormais noté QUANTIN, III).

174.. J. LEBEUF, Mémoires concernant l'histoire civile et ecclésiastique d'Auxerre et de son ancien diocèse, 4 vol., 1743, réed. Auxerre-Paris, 1848-1855, IV, nº 190 (noté LEBEUF).

175.. QUANTIN, III, $\mathrm{n}^{\circ} 299$.

176.. Acte daté du jeudi après la saint Grégoire.

177.. QUANTIN, III, $\mathrm{n}^{\circ} 242$.

178.. QUANTIN, III, $\mathrm{n}^{\circ} 231$.

179.. Autres mains en écritures cursives jusqu'au $n^{\circ} 80$.

180.. Redoublement du numéro.

181.. QUANTIN, III, $\mathrm{n}^{\circ} 71$.

182.. Ajout d'une autre main très proche de la précédente qui a inséré deux actes [ $\mathrm{n}^{\circ}$ $101,102]$ en leur affectant le même numéro lxxxxix, utilisé donc trois fois.

183.. Charte barrée d'une grande croix sur toute le colonne de gauche de la page.

184.. QUANTIN, III, $\mathrm{n}^{\circ} 466$.

185.. Mention insérée sans doute après grattage.

186.. Mention en pas de page avec renvoi marginal.

187.. Sans titre, ni numéro, ni initiale rubriquée.

188. Charte barrée.

189.. Autres mains en écriture cursive jusqu'au nº 138 .

190.. Ajout par une autre main.

191.. Jusqu'au n ${ }^{\circ} 187$ les actes sont copiés d'une écriture moins régulière, plus espacée et anguleuse.

192.. QUANTIN, III, $\mathrm{n}^{\circ} 594$.

193.. Non copié.

194.. Erreur de numéro.

195.. Numérotation CCXI manquante.

196.. Autre main. Dans la table la mention de cet acte est insérée au $n^{\circ} \mathrm{CCXXI}$ sous le titre : Carta de triginta solidos quos datus nobis prior de sancto Saluatore.

197.. Sic

198.. Sic

199.. Autre main qui copie les actes $n^{\circ} 243$ et 244 .

200.. Changement d'écriture.

201.. Changement d'écriture qui reste plus cursive jusqu'au $n^{\circ} 252$.

202.. Copie en français d'une autre main qui écrit également l'acte suivant.

203.. Copie en latin.

204.. Plusieurs mains se succèdent jusqu'au numéro 261.

205.. La nouvelle numérotation correspond à une autre phase de transcription comportant plusieurs mains dont certaines assurent la copie sur plusieurs folios.

206.. Autre main sans numéro. 
207.. Le scribe a copié en guise de datation du quantième : dicta die sabbati comme pour faire référence à la charte précédente.

208.. La charte porte la datation 1295 , le samedi en la fête de saint Matthias apôtre ce qui ne concorde pas avec les calendriers selon lesquels le 24 février de cette année là était un jeudi.

209.. L'acte est daté du mercredi avant la saint Vincent. Plusieurs saints étant commémorés sous ce nom nous avons daté par rapport à l'évêque de Troyes.

INDEX

Index géographique : France/Auxerre

Mots-clés : cartulaire, Saint-Germain d'Auxerre

AUTEUR

NOËLLE DEFLOU-LECA

Université de Grenoble II- ARTeHIS UMR 5594 